\title{
Light Water Reactor Sustainability Program Power Uprate Research and Development Strategy
}

September 2011
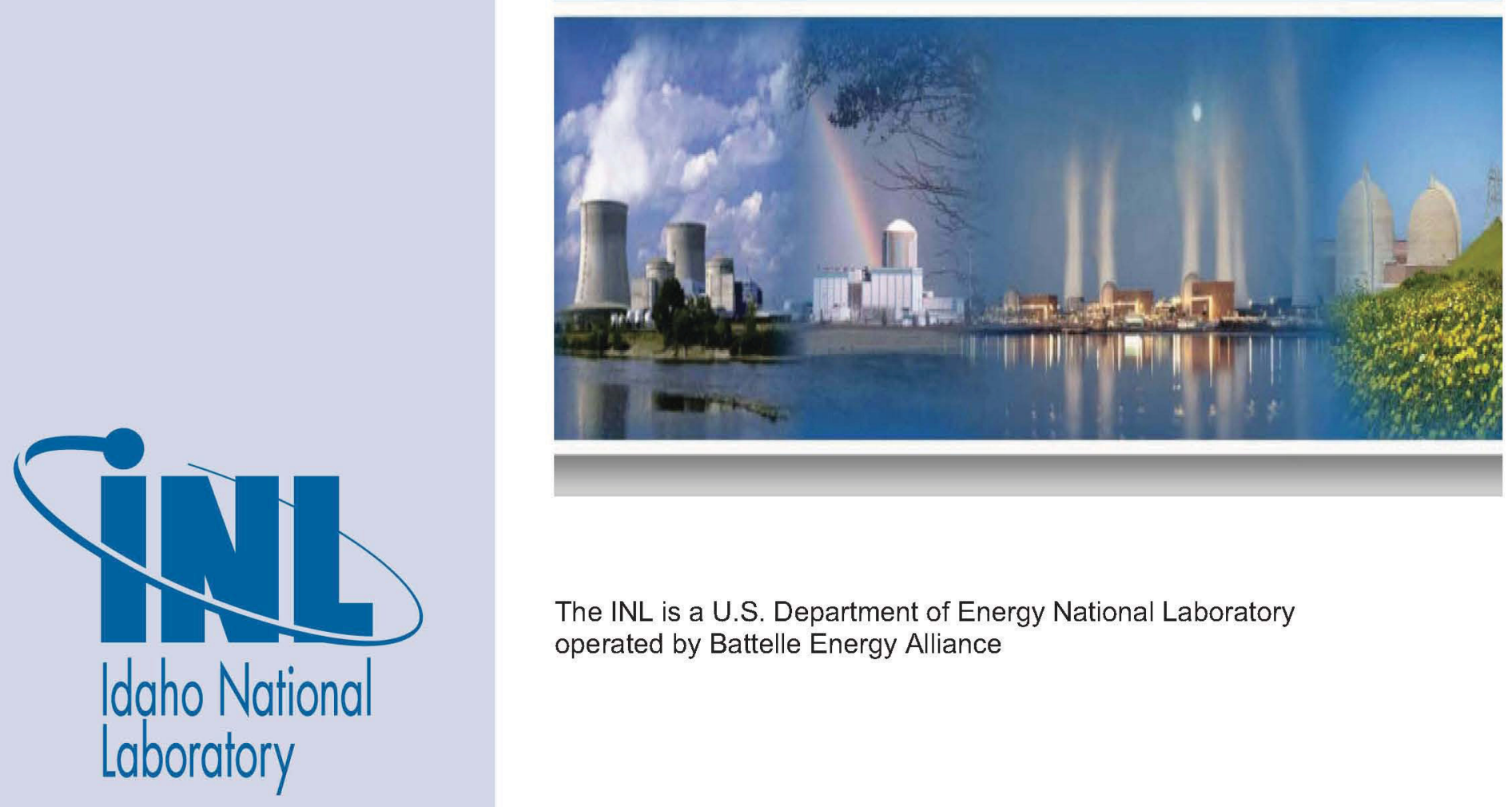

The INL is a U.S. Department of Energy National Laboratory operated by Battelle Energy Alliance 


\section{DISCLAIMER}

This information was prepared as an account of work sponsored by an agency of the U.S. Government. Neither the U.S. Government nor any agency thereof, nor any of their employees, makes any warranty, expressed or implied, or assumes any legal liability or responsibility for the accuracy, completeness, or usefulness, of any information, apparatus, product, or process disclosed, or represents that its use would not infringe privately owned rights. References herein to any specific commercial product, process, or service by trade name, trade mark,

manufacturer, or otherwise, do not necessarily constitute or imply its endorsement, recommendation, or favoring by the U.S. Government or any agency thereof. The views and opinions of authors expressed herein do not necessarily state or reflect those of the U.S. Government or any agency thereof. 


\section{Light Water Reactor Sustainability Program}

Power Uprate Research and Development Strategy

September 2011

\section{Idaho National Laboratory Idaho Falls, Idaho 83415}

http://www.inl.gov

Prepared for the U.S. Department of Energy Office of Nuclear Energy Under DOE Idaho Operations Office

Contract DE-AC07-05ID14517 


\section{EXECUTIVE SUMMARY}

The economic incentives for low-cost electricity generation will continue to drive more plant owners to identify safe and reliable methods for increasing the electrical power output of the current fleet of nuclear power plants. Power uprate enables a nuclear power plant to increase its electrical output with low cost.

Additionally, large power uprates require significant capital investments for plant modifications. These investments also are required to extend the lifetime of the aging nuclear power plant fleet. Therefore, power uprates can help the plant owners recover the investment costs and incentivitize them to invest in long-term operations. However, power uprates bring new challenges to plant owners and operators. These challenges include safety margin loss, equipment damage, or degraded performance and unanticipated responses to plant operating conditions. These problems have arisen mainly from using dated design and safety analysis tools, which resulted in insufficient understanding of the full implications of the proposed power uprate. It is essential to demonstrate that all required safety margins have been properly retained and the existing safety level has been maintained or even increased, with consideration of all conditions and parameters that have an influence on plant safety. Advanced analytical methodologies and tools are required to remove the conservatism and to recover the margin loss to accommodate power uprates. The research and development strategies presented in this document focus on developing advanced analytical tools to support additional power uprates. 


\section{CONTENTS}

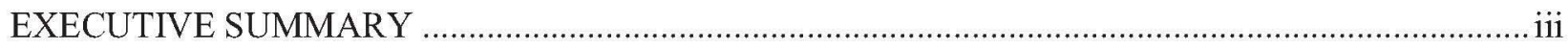

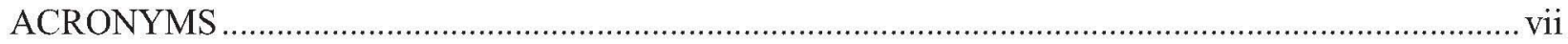

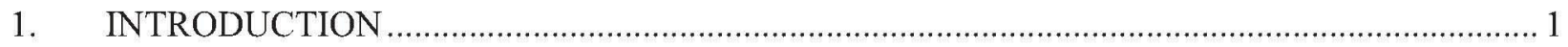

2. LIGHT WATER REACTOR SUSTAINABILITY PROGRAM'S ROLE IN ENABLING

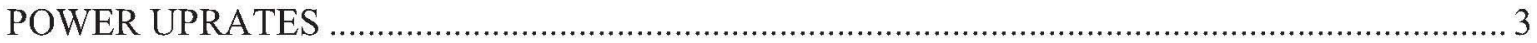

3. CHALLENGES ASSOCIATED WITH POWER UPRATES …….......................................... 3

4. POWER UPRATE RESEARCH AND DEVELOPMENT DRIVERS ........................................... 4

5. RESEARCH AND DEVELOPMENT STRATEGY ….......................................................... 5

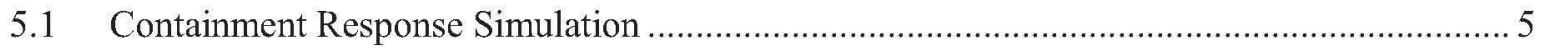

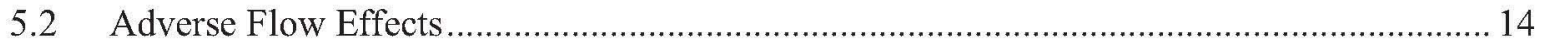

5.3 Departure from Nucleate Boiling Characterization .................................................. 16

5.3.1 Changes of Operating Conditions Due to Extended Power Uprates ......................... 17

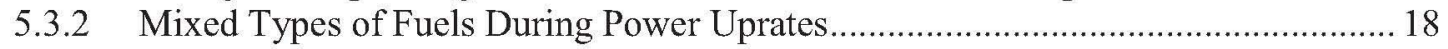

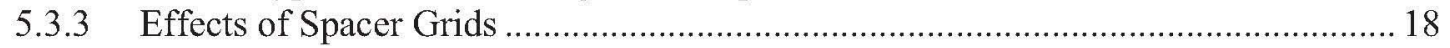

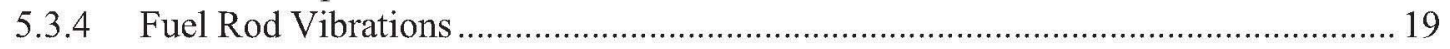

5.3.5 Determination of Inception of Local Boiling ...................................................... 19

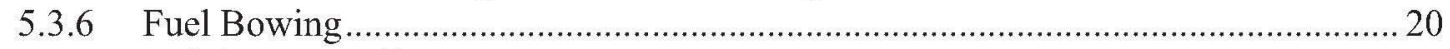

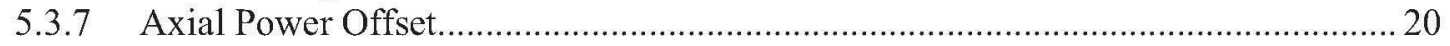

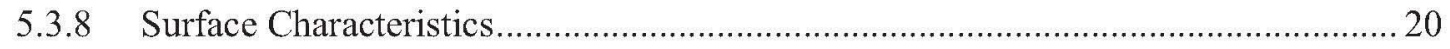

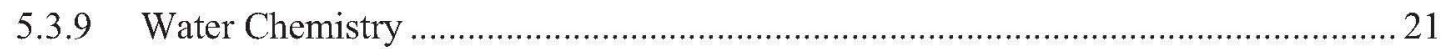

5.3.10 Future Research Needs on Departure from Nucleate Boiling-Type Critical

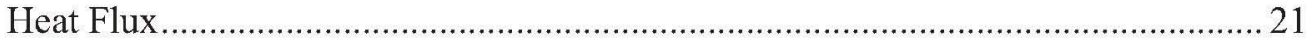

5.4 Spent Fuel Pool Criticality Margin and Coolability......................................................... 21

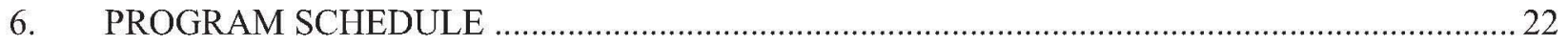

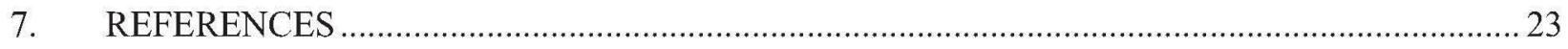

\section{FIGURES}

1. Research and development drivers for power uprates ….................................................... 5

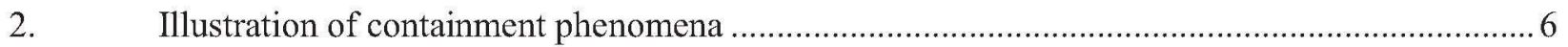

3. Conceptual models for AP-1000 containment mixing (Woodcock et al. 2001)...................... 
4. Sketch of a stratified environment development due to a heat source, showing motions in the plume and environment

5. Typical jet types: (a) pure plume; (b) pure jet; (c) buoyant jet; (d) ceiling jet; (e) wall jet due to impinged jet; and (f) free wall jet due to wall boundary flow

6. Schematic diagram of the two-plume filling box, where $\mathrm{F}$ is the buoyancy flux (courtesy of Wong and Griffiths 1999)....

7. The environment buoyancy profiles fe for $\Phi=0.1, \zeta$ is the non-dimensional depth and $\Phi$ the ratio of the flux of the weak source to the total buoyancy flux.

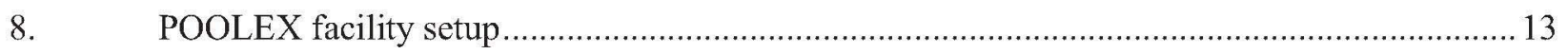

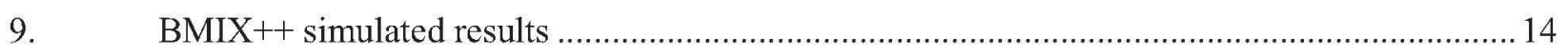

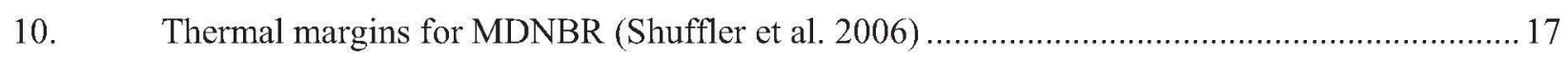

11. Critical heat flux predictions at a pressure of $14.5 \mathrm{MPa}$ (Han et al. 2006)............................. 18

12. Critical heat flux enhancement ratio versus the vibrational Reynolds number at a departure from nucleate boiling condition

13. Critical heat flux ratio versus local quality.

\section{TABLES}

1. Schedule for research and development activities for power uprates .22 


\section{ACRONYMS}

BMIX++ Berkeley mechanistic MIXing code in $\mathrm{C}++$

BWR boiling water reactor

CASL Consortium for Advanced Simulation of Light Water Reactors

CFD computational fluid dynamics

CHF critical heat flux

DNB departure from nucleate boiling

EPU extended power uprate

LWR light water reactor

LWRS Light Water Reactor Sustainability

MUR measurement uncertainty recapture

NRC Nuclear Regulatory Commission

PWR pressurized water reactor

SPU stretch power uprate 


\section{Light Water Reactor Sustainability Program Power Uprate Research and Development Strategy \\ 1. INTRODUCTION}

The maximum power level that nuclear power plants are legally allowed to operate at is set by the plant's operating license and controlled through the plant's technical specifications. Utilities are allowed to increase their maximum power level through a process called a power uprate. It is critical that adequate safety and operating margins are maintained at uprated plant conditions. A power uprate is achieved by requesting a license amendment and providing proper justification and safety analysis to the Nuclear Regulatory Commission (NRC). For a power uprate to be approved by NRC, a comprehensive safety analysis, including environmental effects, must be performed. A number of physical plant modifications may be required and implemented to allow operation at the increased levels of power and to ensure operation within the constraints and framework of the power plant. The nuclear industry has been pursuing power uprate projects since the 1970 s as a valuable way to increase power output in order to keep up with the steady increase in demand for power in the United States. Three types of power uprates are defined by NRC (NRC 2011b):

- The first type of power uprate is called a measurement uncertainty recapture (MUR) power uprate. MUR uprates are less than $2 \%$ and are achieved by implementing enhanced techniques for calculating reactor power through the secondary heat balance. These power uprates typically involve installation of more accurate feedwater flow instrumentation. More precise measurements reduce the degree of uncertainty in the power level, which is used by analysts to predict the ability of the reactor to be safely shutdown under postulated accident conditions.

- The second type of power uprate is called a stretch power uprate (SPU). SPUs are typically between 2 and $7 \%$. SPUs usually involve changes to instrumentation setpoints, but do not typically involve major plant modifications; rather they are achieved through improved fuel performance and improved safety analysis to maintain operating margin.

- The final type of power uprate is called an extended power uprate (EPU). EPUs are typically greater than $7 \%$ and have been approved as high as $20 \%$. EPUs typically involve major plant modifications, including replacement of steam generators, reactor coolant pumps, upgrading the main turbines, upgrading the main generator, upgrading or replacing the main transformers, and other balance of plant upgrades (including cooling towers and ultimate heat sink). Engineered safety systems (such as emergency core cooling system and containment safeguard systems) also are upgraded.

As of July 2011, NRC has approved 139 power uprate applications (NRC 2011c). The total extra power generated from power uprates is equivalent to that of building six new 1,000-MWe nuclear power plants. The industry has achieved such remarkable performance through plant modifications and application of best-estimate modeling and simulation methodologies to recover the conservatism in design and safety analysis.

The majority of the approved power uprates is MUR or SPU. The SPU initially was the dominant project type in the United States due to the ease of implementation and low cost. For most nuclear power plants, original design analyses were performed at $105 \%$ of rated thermal power to provide added margin. With this design margin came margin in the basic steam-cycle design; therefore, only instrumentation setpoint changes are typically required with a SPU. As of July 2011, NRC has approved 65 SPUs. In the late 1990s, state-of-the-art, ultrasonic feedwater flow measurement devices were developed and installed at numerous nuclear power plants to provide a more accurate determination of reactor thermal power and, consequently, enabled MURs. At the same time, fuel design evolutions were being introduced with significant improvements in fuel performance, leading to the ability to core designs with higher fuel enrichments and operate to higher exposures. This improvement in fuel capability opened the door for 
vendors and utilities to explore EPU projects. The EPUs were most achieved in the direct-cycle boiling water reactor (BWR) designs. As of July 2011, 22 EPUs have been approved. Among those, seven are for pressurized water reactors (PWR) and fifteen are for BWRs, representing only $10 \%$ of the PWR fleet and $40 \%$ of the BWR fleet. Therefore, opportunities still exist to apply EPUs to the majority of the operating light water reactors (LWRs), especially PWRs, to further enhance the value of the nuclear fleet asset. Advanced technology has allowed production of new and better replacement components (such as better shape and size of turbine blades, rotors, and casings). These new parts make the turbines more efficient. In addition to producing more electricity, these component upgrades improve the reliability of the plants and support plant lifetime extensions.

Plant modifications require in-depth safety analyses to evaluate the possible safety impact. The analyses have to consider all consequences of the plant modifications with respect to the existing safety margins. The analyses must consider the core characteristics and plant behavior, taking into account the capability of the systems and the reactor protection system setpoints. One key issue in improving plant operating performance is accurate determination of the available plant safety margin. Safety margins are characterized as the difference, with a certain confidence level, between calculated parameter values (such as peak clad temperature, maximum reactor coolant system pressure, and containment pressure under accident conditions such as loss of coolant accident) and the associated licensing limit. Safety margin determination includes considering the modeling and simulation tools and methodologies, the prediction capability and uncertainty quantification, the licensing acceptance criteria, and the accuracy of plant measurements. The safety analyses must demonstrate that the proposed new configuration remains safe and safeguard measures continue to be in place to protect the health and safety of the public. NRC reviews these complex analyses, which span many technical disciplines, before a request for a power uprate is approved. Operation at power uprate conditions can increase the duty on major systems and components, primarily due to higher steam flows, fluence, and temperatures experienced at the uprated conditions. The increased duty may cause degraded performance or even component damage. For example, flow-induced vibration and acoustic-induced vibration have been identified as key areas where increased duty is expected following a power uprate. Several BWRs have experienced damage to their steam dryers at EPU conditions. These problems have arisen mainly from inadequate analysis and understanding of the full implications of the proposed power uprate due to the fact that industry still relies on vintage design and safety analysis tools. It is essential to conduct a comprehensive review of plant conditions prior to implementation of a power uprate to demonstrate that all required safety margins have been properly retained and the existing safety level has been maintained or even increased, with consideration of all conditions and parameters that have an influence on plant safety. Advanced testing and analytical techniques also are needed to address the consequences of changes in operating conditions.

Uprating a nuclear power plant reduces the operating cost per unit energy generated and significantly enhances the asset value to the plant owner. The economic incentives for low-cost electricity generation will continue to drive more nuclear power plant owners to pursue uprating of their nuclear power plant(s). Through implementation of additional upgrades to the physical structures, systems, and components and new safety analysis improvements, existing nuclear power plants are theoretically able to sustain higher power uprates than those already achieved. However, increasing the power level of a nuclear power plant up to $20 \%$ (or potentially greater than $20 \%$ ) of its approved rating will require higher power density core designs and an enhanced scientific understanding of plant performance issues. For example, the integrity of BWR steam dryers and PWR steam generators under the increased steam loads at higher pressure levels must be ensured. Also, the integrity of reactor pressure vessels and core internals due to increased radiation damage and corrosion must be protected. Additional requirements to be satisfied include confirmation of accident-based safety limits for ensuring fuel integrity (increased duty conditions) and containment integrity (higher reactor coolant system storage energy). Additionally, the impact of the power uprate on plant life management for long-term operation also is an important issue. The enabling technologies and scientific understanding being developed in the LWRS Program can address the uncertainties inhibiting the potential for additional EPU applications. Development of deep science-based 
knowledge in this area will be augmented by the Energy Innovation Hub for Nuclear Energy Modeling and Simulation, which is run by the Consortium for Advanced Simulation of Light Water Reactors (CASL). Integrating the results from CASL, plant changes and operating conditions will be evaluated by the LWRS Program to facilitate the implementation of these new EPUs.

The ability to greatly uprate an existing nuclear power plant provides a national strategic benefit of increasing the total available electrical power supply from carbon-free generation sources at a lower cost per $\mathrm{kW}$ while the building of new nuclear plants progresses. The previous success of power uprates makes this approach an attractive way to expand the domestic base of carbon-free electricity supplies and further the nuclear renaissance in the United States.

\section{2. $\quad$ LIGHT WATER REACTOR SUSTAINABILITY PROGRAM'S ROLE IN ENABLING POWER UPRATES}

It is in the best interest of the United States to keep the current fleet of nuclear power plants operating at high levels and keep them in service to produce carbon free electricity as long as they can be maintained safely. However, the nuclear power plant owners would keep them operating only if the nuclear power plants are safe and economically viable. The LWRS Program aims at addressing the longterm and high-risk technical issues of enabling long-term operation beyond 60 years for the current fleet of LWRs. Its primary goals include enhancing the safety and economic performance of the current fleet. Power uprates have significantly contributed to improving the economic viability of the current fleet. In addition, power uprates normally require replacements and modernization of many components; therefore, they contribute to safety improvement of a nuclear power plant. The long-term and high-risk challenges with regards to lifetime extension also confront power uprates. Consequently, the research and development activities planned in the Nuclear Materials Aging and Degradation, Advanced LWR Nuclear Fuel Development, Advanced Instrumentation, Information, and Control Technology, and Risk-Informed Safety Margin Characterization Research and Development Pathways are directly applicable to power uprates. However certain challenges are unique to power uprates and require dedicated research and development resources to address the obstacles.

\section{CHALLENGES ASSOCIATED WITH POWER UPRATES}

Power uprates involve many technical disciplines and complex technical issues. Power uprate projects have high visibility and require detailed technical review by NRC. During power uprate application reviews, unexpected, hidden, and emerging issues are often identified. Significant modifications to the plant for EPUs also require approval by NRC's Advisory Committee on Reactor Safeguards. Detailed analyses have to be submitted for an EPU application. These analyses include (1) equipment performance (such as pressure vessel components, piping, containment response, instrumentation, power generation equipment, emergency core cooling system equipment) under EPU; (2) decay heat loads in containment and fuel pool; (3) source term and impacts on accident events; (4) plant life issues such as fluenceincreased fluence effect on the pressure vessel and flow-accelerated corrosion on piping and components; (5) plant safety analysis impacts; (6) grid impact studies, including interconnection request and studies, and transmission upgrades; and (7) environmental impact studies, including thermal discharge impact and water usage. Detailed work scope descriptions for an EPU can be found in the Nuclear Energy Institute's power uprate program development and implementation roadmap (NEI-08-10).

The following provides a list of issues identified by NRC (Mendiola 2011) and through interactions with the industry:

1. Containment response, including the issue associated with containment accident overpressure credit

2. Steam dryer structural integrity; this resulted from the adverse flow effects at uprated conditions

3. Spent fuel pool criticality 
4. Steam generator tube rupture single failure analysis

5. High-energy line break analyses

6. Fuel transition considerations, including fuel loading challenges for an EPU core plus 24-month fuel cycles and fuel performance issues. The operating envelope (e.g., fuel and coolant temperature and cladding oxidation) for the fuel assemblies in an EPU core may exceed current operating experience. Crud-induced power shift remains a constraint and a safety concern. Fuel assembly distortion (rod bow and assembly bow) will increase.

Other important effects on power uprates include reduction in time available for operator actions; increased irradiation-assisted stress corrosion cracking of core internals; flow-accelerated corrosion; fatigue of feedwater piping; anticipated transient without scram; local power oscillations; post-loss-ofcoolant-accident boron acid mixing and precipitation; thermal conductivity degradation; gas accumulation; GSI-191; digital instrumentation and control; human factors; alternate source term; and auxiliary feedwater upgrades. NRC (NRC 2010) also documented the challenges associated with power uprates. These include containment accident overpressure and adverse flow effects (flow-induced and acoustic-induced vibrations).

Most of these challenges are associated with the inadequacy of existing vintage analytical tools to analyze and predict component performance and plant response. The research and development activities laid out in this document will concentrate on developing and validating new design and safety analysis tools.

\section{POWER UPRATE RESEARCH AND DEVELOPMENT DRIVERS}

With an aging LWR fleet, plant modifications and modernization will become essential for gaining safety margins by enhancing the plant power-limiting equipment capability. More reliable and accurate reactor safety analyses are required to demonstrate margin recovery to accommodate power uprates. To do so, some key phenomena will have to be better understood and modeled, such as containment response; critical heat flux (CHF) considering water chemistry; flow-induced vibration and acoustic coupling to system response; and spent fuel pool criticality and coolability. Based on extensive interactions with the industry and EPRI, among all of the challenges presented in Section 3, the containment response issue, especially the containment accident overpressure credit issue, is the obstacle issue that had prevented a number of nuclear power plants from getting EPU applications approved. Containment response phenomena include containment pressure and temperature response, thermal mixing/stratification and gas transport in containment, transient structural response of containment vessels to loads, and condensation and mixing/stratification in the BWR suppression pool. The current containment analysis tools, based on lumped parameter models, are not adequate to address this issue. The steam dryer integrity issue, due to adverse flow effects with uprated conditions, is second on the list, with a large number of requests for additional information issued by NRC for BWR EPU applications. Long-life and high-performance fuel is very important for power uprates. The experimental capability to characterize departure from nucleate boiling (DNB) to support advanced fuel design has to be reestablished. Additionally, NRC had been questioning the standard practice on the spent fuel pool criticality calculations before Fukushima accidents happened. Post-Fukushima, the spent fuel pool criticality and coolability is becoming even more important.

The research and development drivers will focus on (1) developing mechanistic modeling to improve containment response simulation, (2) developing improved methodology to address adverse flow effects, (3) establishing experimental capabilities to better characterize DNB, and (4) addressing the spent fuel pool criticality and coolability issue. 


\section{High-Power Density Cores}

- Advanced fuels

\section{Address Adverse Flow Effects \\ - Improved analysis Methodology \\ - Advanced component Designs (dryers, separators \& SGs)}

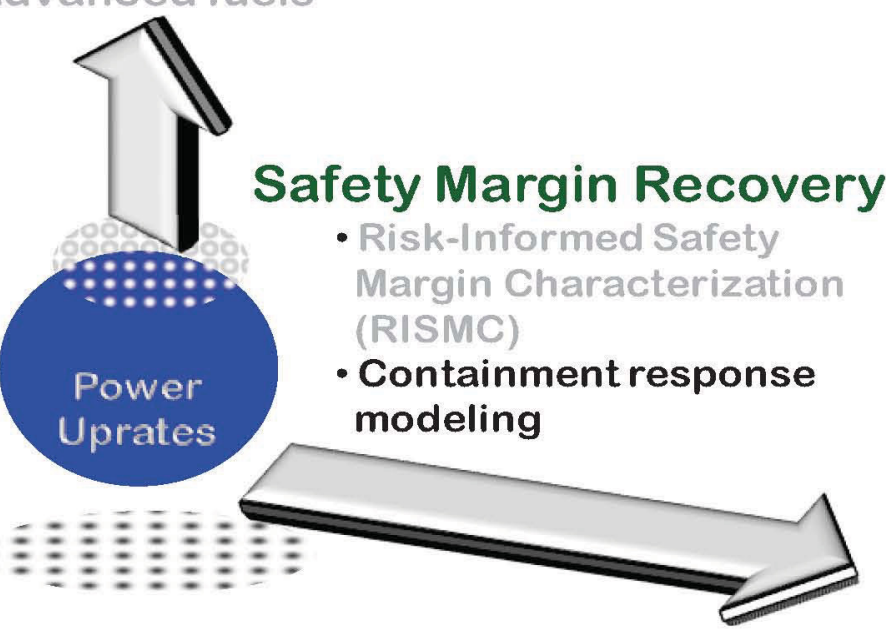

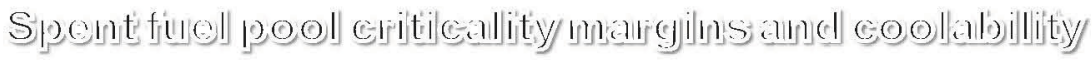

Figure 1. Research and development drivers for power uprates.

\section{RESEARCH AND DEVELOPMENT STRATEGY}

\subsection{Containment Response Simulation}

Containment is one factor that would limit how much uprated power a nuclear power plant can achieve. There are many considerations in containment analyses, such as peak containment pressure and temperature, subcompartment analysis, combustible gas control, containment heat removal (spray and fan cooler), net positive suction head of emergency core cooling system pumps, BWR suppression pool hydrodynamic loads, and BWR drywell bypass. Power uprates would erode safety margins; it is necessary to recover margins to accommodate an increase in power level. For example, EPUs result in a temperature increase of the sump water in PWRs and the suppression pool water in BWRs during certain postulated accidents or abnormal events. This could affect performance of the emergency core cooling system pumps when taking suction from these water sources. Adequate net positive suction head is necessary for the emergency core cooling system and containment heat removal pumps to deliver flow rate. In some cases, utilities have included containment accident overpressure in their safety analyses to demonstrate acceptable performance of the emergency core cooling system pumps. However, this practice had been questioned by the Advisory Committee on Reactor Safeguards. More mechanistic containment thermal hydraulic codes would better simulate the temperature behavior in the containments and eliminate the need to take containment accident overpressure credit.

The state-of-the-art methodology containment analysis codes only have empirical models to simulate some of the very important phenomena in containment (such as thermal mixing and thermal stratification). Other phenomena include forced-flow condensation, entrainment, water aerosols, droplet break flow, and droplet drop-out from atmosphere. The empirical models would not simulate long-lasting events (e.g., the Fukushima accident) very well. Figure 2 illustrates some of the high-level phenomena in containment. This subtask will focus on the areas highlighted in yellow. The focus areas are containment thermal hydraulics and gas (hydrogen) transport to address deficiencies in the current models. 


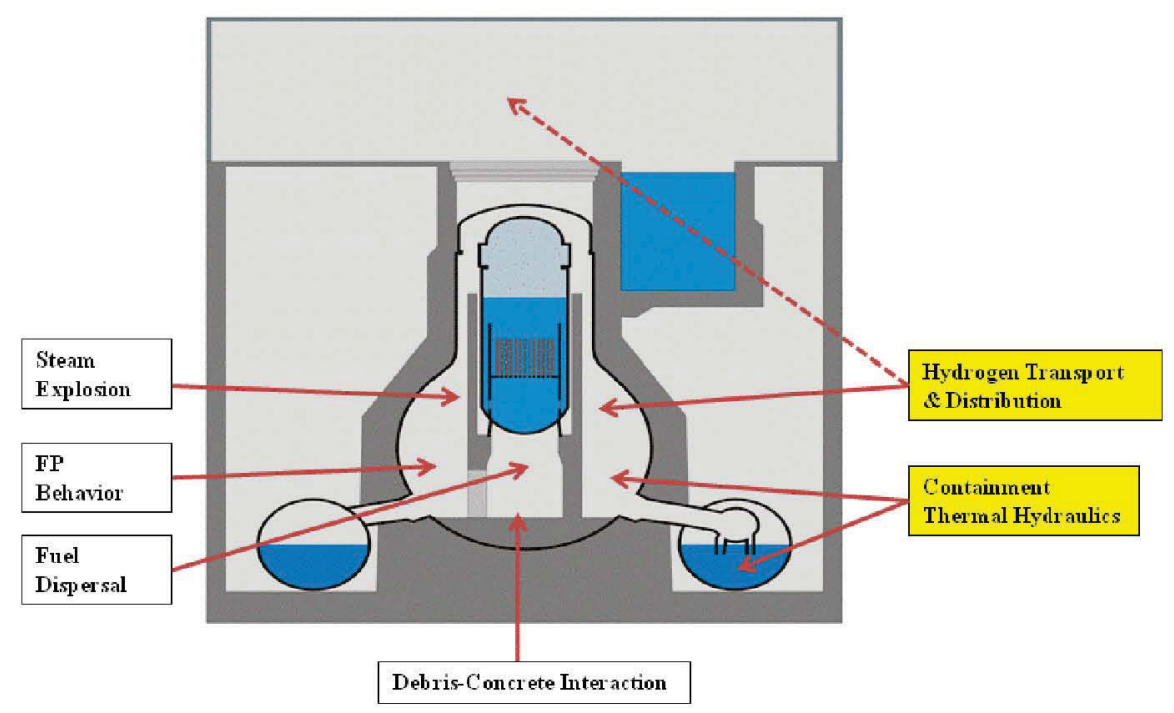

Figure 2. Illustration of containment phenomena.

For both current operating LWRs with active safety features and advanced LWRs with passive safety features, post-loss-of-coolant-accident gas transport between containment compartments and hydrogen distribution have been identified as high-ranking phenomena by several international expert groups because they mostly affect the risk of containment failure (Auban et al. 2007). The 2011 Fukushima accident highlighted the importance of having a better understanding of hydrogen distribution in containment. Mixing, stratification, and gas transport phenomena are very important for reactor systems' safety with large enclosures such as containments. These include post-loss-of-coolant-accident gas transport between containment compartments and hydrogen distribution in operating LWRs, as well as suppression pool and isolation condenser pool steam condensation and mixing in existing BWRs. It is very important to accurately predict fluid temperature, density, and concentration distributions for both design optimization and safety analysis of the containment. However, individual transport mechanisms governing mixing in containments are characterized by time and length scales that can differ by orders of magnitude. The large volumes and the complexity of the interactions of different flow and thermal structures make analysis a daunting task. The accompanying large analysis uncertainty often casts doubts about the claimed large safety improvement by Gen-III+ passively safe LWRs over the operating Gen-II actively safe LWRs. Because of these reasons, large-scale experimental projects (like programs performed at PANDA [PSI, Switzerland]) have been continuously investigating these phenomena over the past two decades (Paladino et al. 2011). The Organization for Economic Cooperation and Development-sponsored SETH project investigates mixing and distribution of steam/air/helium at a large scale in multi-dimensional, multi-compartment geometry in order to resolve some safety-related issues in containment thermal-hydraulics. The SETH project was launched in 2001 with 15 participating countries and is still ongoing. The United States has fallen behind Europe because of the little investment in containment safety study over the past decade.

Even though the nuclear power industry in the United States has achieved remarkable safety performance in the last 30 years (post Three-Mile Island), there had been quite a few safety near misses. For example, in March 2002, it was discovered that boron acid corrosion on the reactor head almost caused a loss-of-coolant accident at the Davis-Besse plant. Therefore, even though the loss-of-coolant accident and subsequent potential containment failure have low probability, they cannot be ignored. Continuous research should be invested to gain insights into these less understood post-loss-of-coolantaccident phenomena. The 2011 Fukushima accident further highlighted the importance of research and development to better understand containment response under accident conditions. 
In BWRs, the long-term, post-accident containment pressure is determined by the combination of noncondensable gas pressure and steam pressure in the wet well gas space. The suppression pool surface temperature, which determines the vapor partial pressure, is very important to the overall containment performance. Therefore, thermal stratification of the suppression pool due to blowdown is of primary importance (Gamble et al. 2001). The majority of the Gen-II LWRs that share similar active engineered safety features as those used by the Fukushima reactors will continue to operate for a very long time. To support safe and economical long-term operation of existing LWRs, advanced modeling and simulation tools should provide prediction capability and help find potential mitigation measures to further improve nuclear power plant safety. As one of the important components in containment thermal hydraulics study, high fidelity and efficient thermal mixing and stratification models are indispensable for nuclear power plant system safety analyses. The containment design used conservative assumptions regarding mixing and condensation. Improved thermal mixing modeling capability would increase confidence on the containment response and allow further power uprate to improve economics.

Gen-III+ LWRs (e.g., ESBWR and AP-1000) rely on passive safety-grade containment systems to reduce cost and improve safety. As a result, certain phenomena (e.g., thermal mixing and stratification in large enclosures) have become important. Moreover, stronger coupling between the primary systems and containment-in-accident conditions requires integrated simulation of both systems (Oriolo and Paci 1996). AP-1000's design uses a passive containment cooling system to remove decay heat. Mass transfer is the dominant means of containment heat removal on both inner and outer steel shell surfaces (Woodcock et al. 2001). As shown in Figure 3 (on the inside), condensation on the containment shell dominates heat removal and is strongly influenced by distribution of steam and noncondensible gases. During the postblowdown phase of a loss-of-coolant accident transient, mixing (due to break momentum) may be neglected by assuming momentum to be dissipated within the break compartment, conservatively minimizing source momentum-induced mixing. One or more buoyant plumes will rise from openings in the operating deck, and a wall boundary layer, induced by heat and mass transfer to the containment shell, will flow downward. Both the plume and wall layer entrain bulk mixture, acting to circulate the bulk mixture. The fluid dynamics leads to a time-averaged vertical gradient of steam concentration. The containment design used several highly conservative assumptions regarding mixing and condensation. Improved thermal mixing modeling capability would increase the confidence on the passive containment performance and allow further power uprate to improve economics.

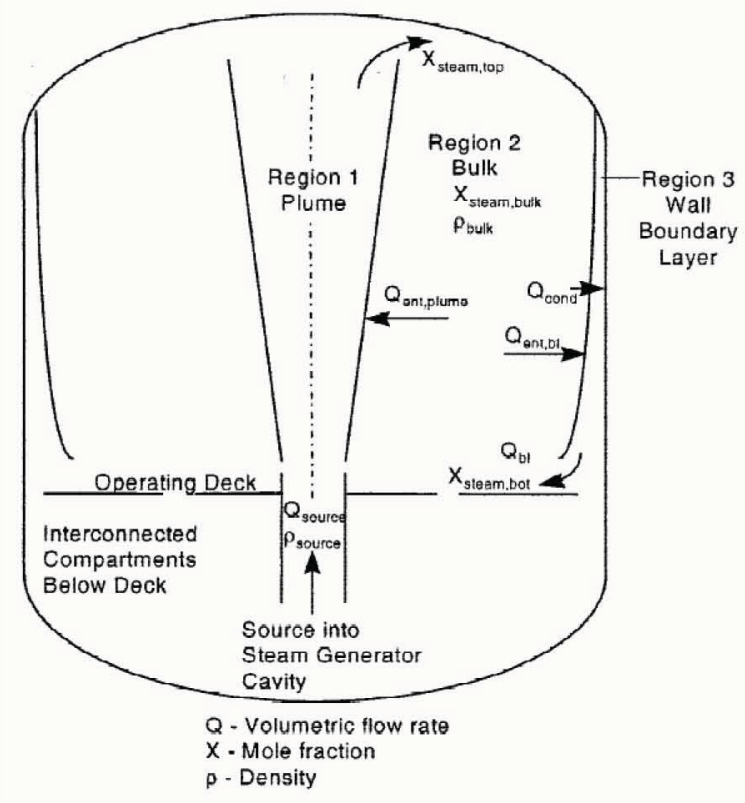

Figure 3. Conceptual models for AP-1000 containment mixing (Woodcock et al. 2001). 
In terms of modeling and simulation efforts in containment mixing, two opposite trends are observed. One is along the traditional system analysis by using decoupled, highly simplified, and conservative zero-dimensional models to study mixing in large enclosures. Another route is to try expensive and inefficient three-dimensional computational fluid dynamics (CFD) simulation. Current major system analysis or severe accident analysis codes (e.g., RELAP5, TRAC, or MELCOR) either have no models or only have zero-dimensional models for thermal stratification in large enclosures. The lack of general thermal mixing and stratification models in those codes severely limit their application and accuracy for safety analysis. While CFD methods can be used to analyze simple configurations, these methods require very fine grid resolution to resolve thin substructures (e.g., jets and wall boundaries); however, fine grid resolution is difficult or impossible to provide for studying the reactor response to transients due to prohibitive computational expenses. In the framework of the fifth Euratom Framework Programmes project ECORA (i.e., Evaluation of Fluid Dynamic Methods for Reactor Safety Analysis), CFD capabilities for simulating flows in containment of nuclear reactors was evaluated (Andreani et al. 2008). The assessment included a first attempt to use best practice guidelines for analysis of long, large-scale, transient problems. Because of the large computational expenses of the analysis, it was concluded that application of the best practice guidelines to full containment analysis is out of reach with the currently available computer power. Without fully following best practice guidelines, the CFD simulation uncertainty cannot be quantified.

Considering the limitations of inadequate zero-dimensional models and inefficient three-dimensional CFD methods, new high fidelity and efficient thermal mixing and stratification methods are needed to improve analysis accuracy and reduce modeling uncertainty, especially for system analysis. The middle path actually has existed and already advanced to a point that could be harvested with modest efforts, based on more than a decade of research in the thermal mixing and stratification field at the University of California Berkeley. Simplified governing equations for stably stratified large enclosures are derived in Peterson's (1994) original paper by applying Zuber's (1991) two-tiered scaling methodology. Based on this method, one-dimensional information can be obtained. The primary objective of this subtask is to develop and implement highly efficient and high-fidelity, one-dimensional, thermal mixing and stratification models for LWR containment transport phenomena.

Previous scaling has shown that stratified mixing processes in large stably stratified enclosures can be described using one-dimensional, partial, differential equations, with vertical transport by free and wall jets modeled using standard integral techniques, which can have different directions than the vertical direction. This allows very large reductions in computational effort compared to three-dimensional numerical modeling of turbulent mixing in large enclosures. The Berkeley mechanistic MIXing code in the $\mathrm{C}++(\mathrm{BMIX}++)$ code was originally developed at the University of California Berkeley to implement such ideas. The code uses a Lagrangian approach to solve one-dimensional transient governing equations for the ambient fluid and uses analytical or one-dimensional integral models to compute substructures. The BMIX++ code has been successfully validated against multiple benchmark problems. Various problems with different combinations can be solved by the BMIX++ code (e.g., multi-component fluid, variable enclosure cross-section area in vertical direction, multi-enclosures, and multiple jets, plumes, and sinks in one enclosure). When steam-water jet and condensation models are available, the code can be applied for containment analysis.

To explain why the one-dimensional method can provide enough information to describe mixing and heat transfer in stratified large volumes, we start with the simplest case. Figure 3 shows the classical "filling box" problem, which demonstrates the major phenomena in stratified mixings (Baines and Turner 1969). The heating source gives rise to a thermal plume that rises and spreads over the top of the enclosure, resulting in a stably stratified layer that increases downwardly with time. The region below the upper stratified layer continues to be at the initial temperature in the enclosure before the onset of flow. The temperature in the upper heated layer decreases downward from the ceiling to the interface between 
the upper and lower regions. The flow pattern, the side entrainment into the plume, and the downward motion of the heated upper layer are shown in Figure 4.

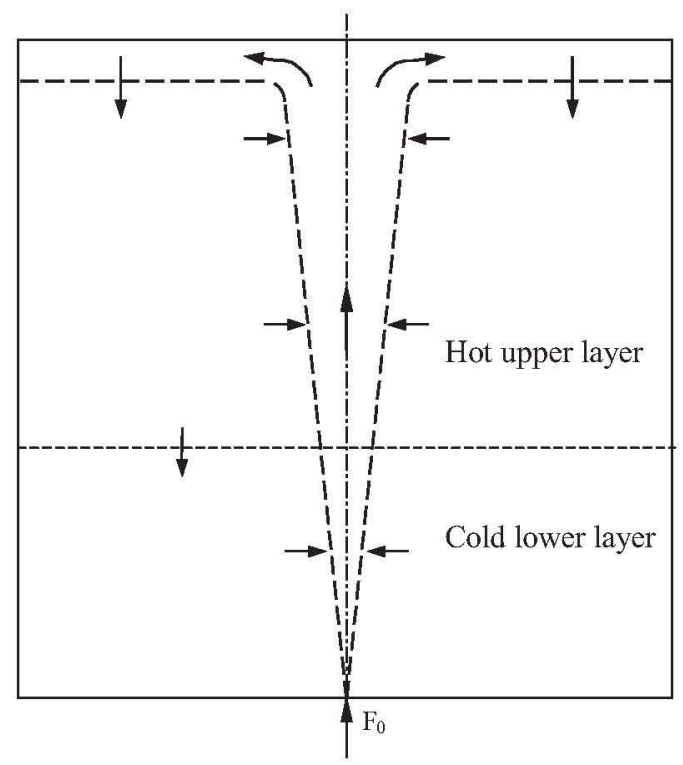

Figure 4. Sketch of a stratified environment development due to a heat source, showing motions in the plume and environment.

Buoyancy-caused plumes, momentum jets, buoyancy jets, and natural convection boundary layer flows (free wall jets) also are common mixing forces that cause stratification. Large enclosures mixed by buoyant plumes and wall jets can normally be expected to stratify. Furthermore, the transition between well-mixed and stratified conditions can be predicted (Peterson 1994). For example, for an injected jet case, the ambient fluid is stably stratified when

$$
\left(\frac{H_{s f}}{d_{b j o}}\right) R i_{b j o}^{1 / 3}\left(1+\frac{d_{b j o}}{4 \sqrt{2} \alpha_{T} H_{s f}}\right)^{2 / 3}>1
$$

where $H_{s f}$ is the height of enclosure, $d_{b j o}$ the diameter of the jet source, $\alpha_{T}=0.05$ Taylor's jet entrainment constant, and the jet Richardson number $(R i)$ is given by

$$
R i_{b j o}=\frac{\left(\rho_{a}-\rho_{o}\right) g d_{b j o}}{\rho_{a} U_{o}^{2}}
$$

where $\rho_{a}$ is the ambient fluid density, $\rho_{o}$ the source fluid density, $g$ the gravity constant, and $U_{o}$ the jet source speed.

Peterson's (1994) scaling analysis has shown that ambient fluid between jets tends to organize into either a homogeneously mixed condition or a vertically stratified condition that can be described by a one-dimensional temperature and concentration distribution. Therefore, we can describe stratified mixing processes in large, complex enclosures using one-dimensional differential equations, with transport in free and wall jets modeled using integral models. The detailed geometry of the enclosure becomes unimportant and only the horizontal cross-sectional area and perimeter must be specified as a function of elevation. This allows very large reductions in computational effort compared to three-dimensional numerical modeling of turbulent mixing in large enclosures. Large enclosures mixed by buoyant plumes 
and wall jets can normally be expected to stratify. For the stratified enclosure, the governing equations for ambient fluid can be derived and written in the following compact form:

$$
A(z) \frac{\partial \mathbf{G}}{\partial t}+\frac{\partial \mathbf{F}}{\partial z}=\mathbf{S}
$$

where $\mathrm{A}(\mathrm{z})$ is the horizontal cross-sectional area of the volume at elevation $\mathrm{z}$, and $\mathrm{G}, \mathrm{F}$, and $\mathrm{S}$ are the vectors of conserved quantities, fluxes, and source terms, respectively

$$
\mathbf{G}=\left(\begin{array}{c}
\rho \\
0 \\
\rho h \\
\rho \chi_{1} \\
\vdots \\
\rho \chi_{n s-1}
\end{array}\right) \quad \mathbf{F}=\left(\begin{array}{c}
\rho Q_{s f} \\
P \\
\rho h Q_{s f}-A k \frac{\partial T_{s f}}{\partial z} \\
\rho \chi_{1} Q_{s f}-\rho A D \frac{\partial \chi_{1}}{\partial z} \\
\vdots \\
\rho \chi_{n s-1} Q_{s f}-\rho A D \frac{\partial \chi_{n s-1}}{\partial z}
\end{array}\right) \quad \mathbf{S}=\left(\begin{array}{c}
-\sum_{k=1}^{n}\left(\rho Q^{\prime}\right)_{k}+\rho S^{\prime}-\rho \hat{S}^{\prime} \\
-\rho g \\
-\sum_{k=1}^{n}\left(\rho h Q^{\prime}\right)_{k}+\rho S_{h}^{\prime}-\rho \hat{S}_{h}^{\prime} \\
-\sum_{k=1}^{n}\left(\rho \chi_{1} Q^{\prime}\right)_{k}+\rho \chi_{1} S^{\prime}-\rho \chi_{1} \hat{S}^{\prime} \\
\vdots \\
-\sum_{k=1}^{n}\left(\rho \chi_{n s-1} Q^{\prime}\right)_{k}+\rho \chi_{n s-1} S^{\prime}-\rho \chi_{n s-1} \hat{S}^{\prime}
\end{array}\right)
$$

where $\rho$ is the mixture density, $\mathrm{h}$ enthalpy, $\chi$ mass fraction, $\mathrm{Q}$ volume flow rate, $\mathrm{P}$ pressure, $\mathrm{k}$ thermal conductivity, T temperature, D mass diffusion coefficient, Q' jet volumetric entrainment rate per unit length, n the total number of jets, $S^{\prime}$ and $\hat{S}^{\prime}$ volumetric source and sink per unit length, $S_{h}^{\prime}$ and $\hat{S}_{h}^{\prime}$ volumetric energy source and sink per unit length, and $n s$ and $s f$ are subscripts denoting the number of species and stratified ambient fluid, respectively.

The BMIX++ code, which was originally developed at the University of California Berkeley (Christensen and Peterson 2001, Zhao 2003, Niu et al. 2007, and Zhao and Peterson 2011), solves mixing and heat transfer problems in stably stratified enclosures. The code uses a Lagrangian approach to solve one-dimensional transient governing equations for ambient fluid and uses analytical or one-dimensional integral models to compute substructures. The numerical methods traditionally used to solve the conservation equations have great difficulty in preserving strong gradients in hyperbolically dominated flows. The traditional first order discretization procedures inherently introduce artificial diffusion terms. Typically, these extra diffusion terms put severe limitations on the maximum size of the computational control volume for the computed solution to be reasonably accurate. Therefore, the BMIX++ code uses the Lagrangian approach (Christensen and Peterson 2001) as an alternative to the traditional numerical methods to do the following:

- Eliminate "false diffusion" from the discretized equations

- Give physically acceptable solutions, even for coarse computational grids

- Have favorable stability requirements (i.e., a very lax stability requirement)

- Require low computational cost.

The Lagrangian formulation tracks the position of constant mass fluid "layers." In practice, the enclosure is divided into a user-specified number of horizontal control volumes. The conservation equations, without the diffusion terms, are used to calculate the new positions, compositions, and enthalpies of the control volumes for each time step. Next, composition and energy are corrected according to the diffusion terms in the conservation equations. This first order scheme algorithm could be improved to reach second order accuracy with advanced algorithms such as the Jacobian Free Newton Krylov method (Knoll and Keys 2004, Mousseau 2005). 
A jet should be understood as a generic concept of any steady continuous flow structure in an ambient volume with a dominant flow direction and a length scale much less than the ambient volume's scale. For example, a plume (due to a heat source), a pure jet (due to an initial momentum source), a buoyant jet (due to both buoyancy and momentum), a ceiling jet (a jet below the ceiling due to a jet impingement), a wall jet along a wall surface, a wall jet (due to a normal jet injection), and a wall boundary flow are all taken as jets. All of these different jets have a common character: the jet entrains fluid from the ambient volume and finally discharges into the ambient volume. Figure 5 shows several typical jets. The BMIX++ code includes a jet model library, including several free jet models for plumes and buoyant jets, a buoyant wall jet model, a ceiling jet model, and two line jet models. A fourth order Runge-Kutta-Fehlberg method, which has the advantage of automatically adjusting the step length to meet any given error tolerance, is selected to solve differential equations for jet models.

The BMIX++ code has been validated successfully against multiple benchmark problems (e.g., stratification in a water tank due to a heater inside, water tank exchange flow experiment simulation, stratification produced by multiple plumes, and the University of California at Berkley's large containment mixing experiment, which is composed of a rectangular enclosure with an isothermal cooling wall and a hot air jet injecting [Zhao 2003]). The following presents application of the BMIX++ code to mixing experiments performed by Wong and Griffiths (1999), where two buoyancy sources produced well-separated, turbulent plumes. Figure 6 gives a schematic diagram of the general two-plume situation. One interesting phenomenon is that the source with the larger buoyancy flux produces a plume that descends to the bottom, while the source having a smaller buoyancy flux produces a plume that spreads at an intermediate depth. They also presented a numerical solution for the mixing process by extending Baines and Turner's (1969) method for a filling box to calculate the mixing process with multiple plumes. Their solution includes one set of a partial differential equation for the ambient and $\mathrm{n}$ sets of a partial differential equation for each plume based on Morton's (1959). They used a finite-difference scheme to solve the equations. Given an ambient density profile, each of the $\mathrm{n}$ sets of plume equations was solved separately using a fourth-order, Runge-Kutta method. Then the ambient density profile was solved according to the solutions for plumes and the ambient governing equations.
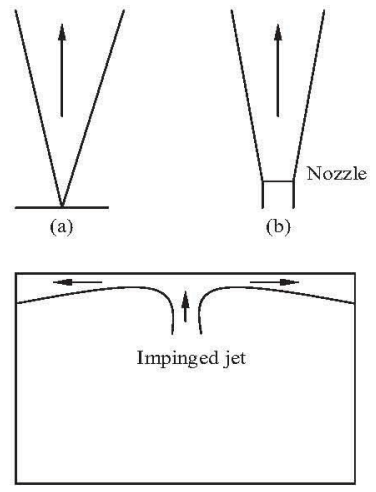

(d)

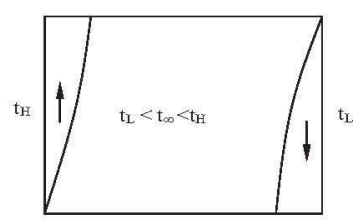

(f)

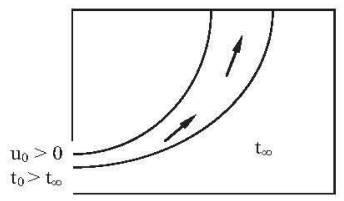

(c)

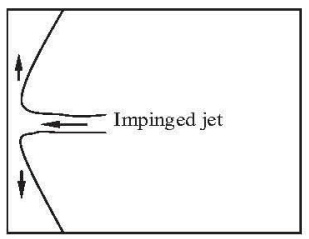

(e)

Figure 5. Typical jet types: (a) pure plume; (b) pure jet; (c) buoyant jet; (d) ceiling jet; (e) wall jet due to impinged jet; and (f) free wall jet due to wall boundary flow. 


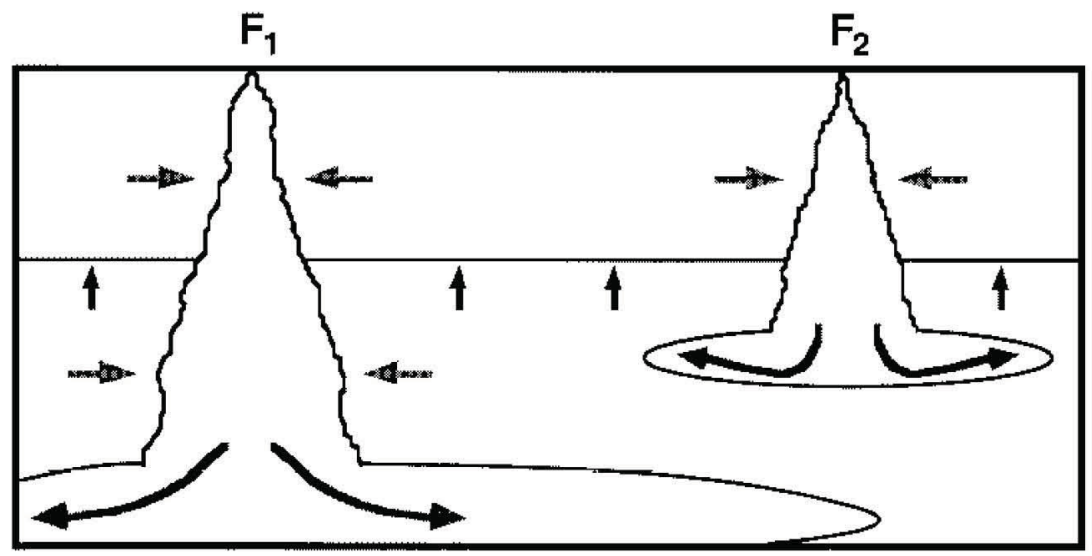

Figure 6. Schematic diagram of the two-plume filling box, where F is the buoyancy flux (courtesy of Wong and Griffiths 1999).

The new profile was used to calculate plume properties and cycle repeats. Wong and Griffiths' method is quite similar to the methods of the BMIX++ code, except that the BMIX++ code uses much more general ideas to calculate the mixing processes (i.e., entrainment and discharge and two-tiered scaling) and uses the Lagrangian method instead of traditional finite-difference method to solve ambient equations. We can say that Wong and Griffiths' method is a special example of the methods used by the BMIX++ code. Therefore, comparison with the experiments and Wong and Griffiths' predictions provides an interesting validation case for the BMIX++ code. The result by the BMIX++ simulation was compared with the experimental data and the prediction by Wong and Griffiths. Figure 7 shows several nondimensional environmental density profiles at different time instances. The predictions by the BMIX++ code and by Wong and Griffiths are very close and agree very well with the experiment, especially for the long-term profiles. It seems that the BMIX++ code gave a little better prediction for the long-term profile than Wong and Griffiths' model. For the short term, both numerical models predicted unreal sharp density variation near discharge levels due to imperfect discharge models.

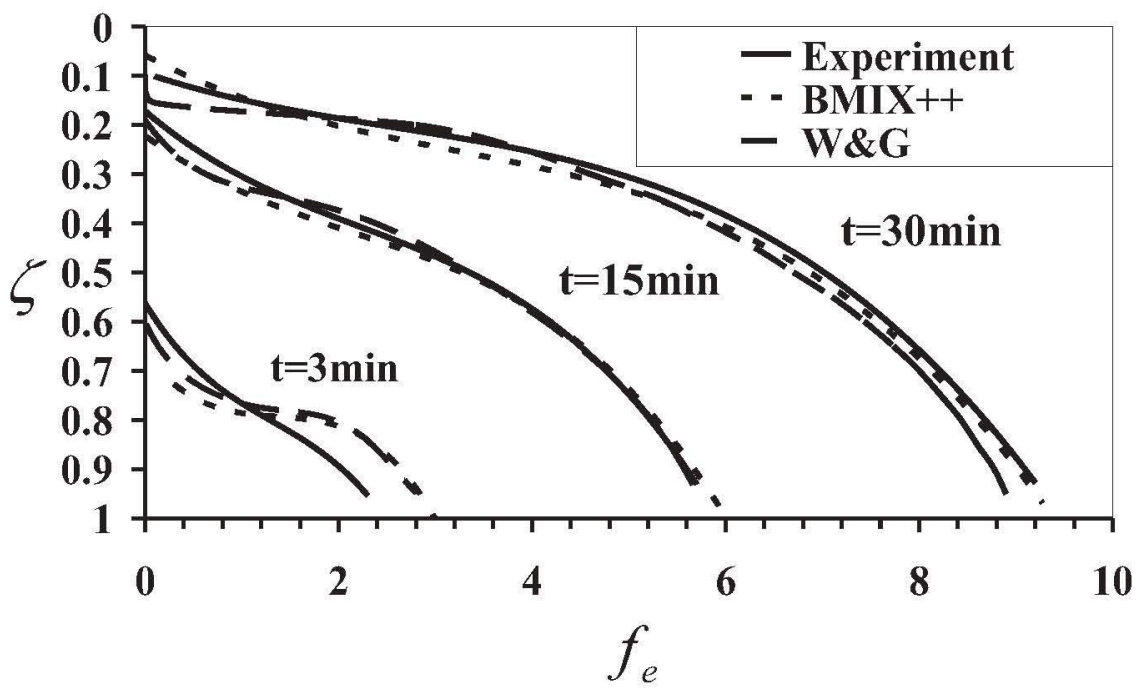

Figure 7. The environment buoyancy profiles fe for $\Phi=0.1, \zeta$ is the non-dimensional depth and $\Phi$ the ratio of the flux of the weak source to the total buoyancy flux. 
The BMIX++ code was recently extended to simulate a BWR suppression pool experiment (POOLEX experiment) conducted in Finland. Figure 8 shows the POOLEX facility setup (Laine and Puustinen 2006). Figure 9 shows the simulated results versus experimental data. BMIX++ simulation results agreed with the experimental data very well. In addition, BMIX++ simulation is 1,000 times faster than CFD simulations. The suppression pool temperature distribution strongly affects the available net positive suction head

NPSHa $=\frac{P_{\text {noncondensable }}+P_{v}\left(T_{\text {surface }}\right)-P_{v}\left(T_{\text {suction }}\right)}{\rho \mathrm{g}}+H_{\text {pool }}-H_{\text {pump }}-H_{\text {loss }}$.

If one uses the temperature distribution in the simulated POOLEX experiment as an example, a $35^{\circ} \mathrm{C}$-temperature difference between the pool surface temperature and the emergency core cooling system pump suction would translate into about $2.8 \mathrm{~m}$ or $30 \%$ of net positive suction head required. This effect had not been analyzed in the existing net positive suction head sensitivity analysis, though this effect is far larger than any single effect considered (NRC 2011a).

The POOLEX experiment simulation demonstrates the ability of the BMIX++ code to simulate complex thermal stratification and mixing problems. However, it also shows the need to couple the BMIX++ code with a system analysis code in order to fully utilize this high-efficiency and high-fidelity code. After all, the dynamic changes on the jet sources can only be efficiently calculated by a system code. Similar extension and coupling of the BMIX++ code with a system analysis code is possible for LWR applications, although a multi-year effort is needed because of the complex multi-phase mixing and heat transfer phenomena in LWR containments and the work to couple two codes together. The BMIX++ was written in $\mathrm{C}++$ programming language and developed with fully object-oriented programming techniques, which makes the code highly flexible to evolve with time.

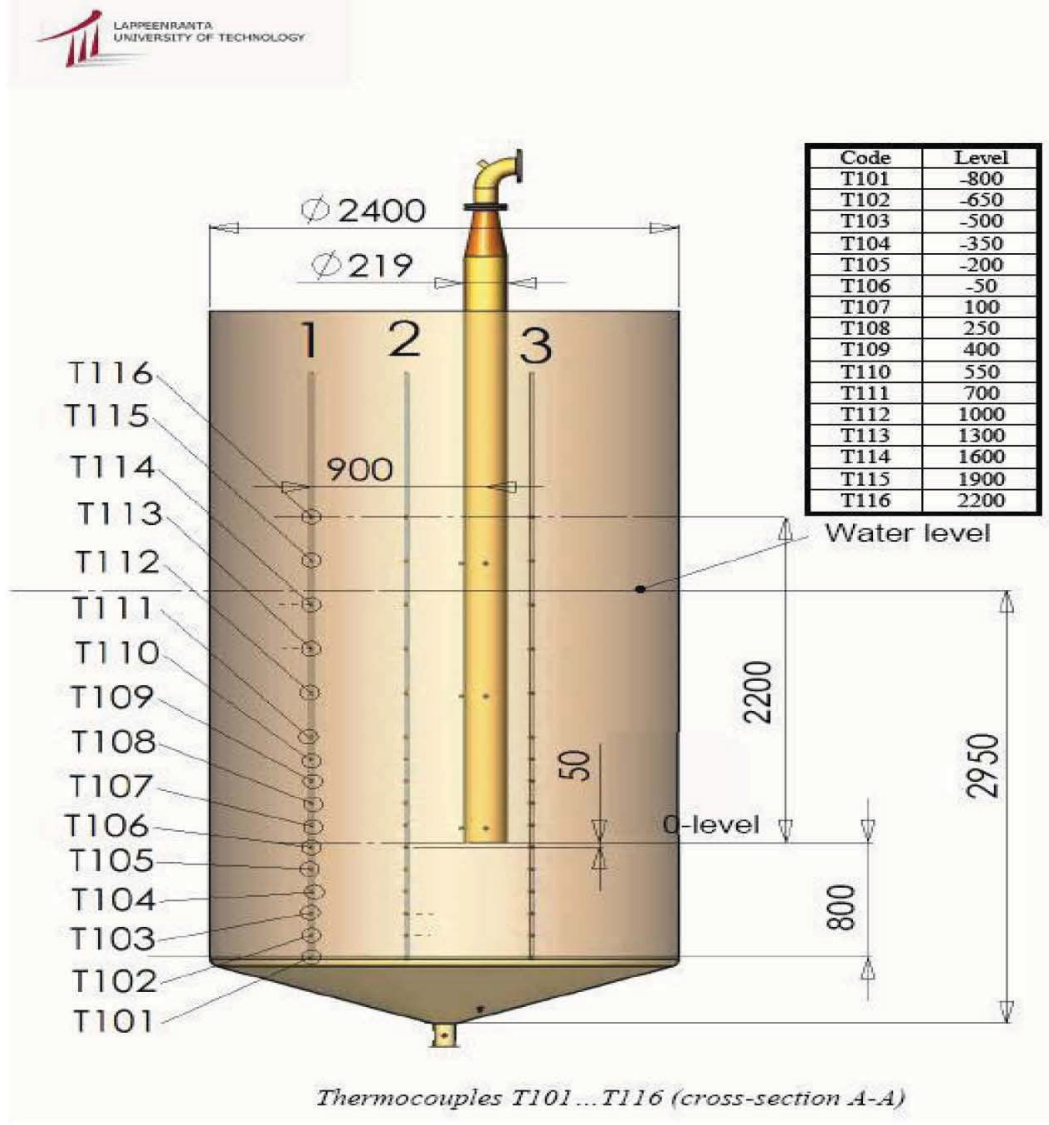

Figure 8. POOLEX facility setup. 


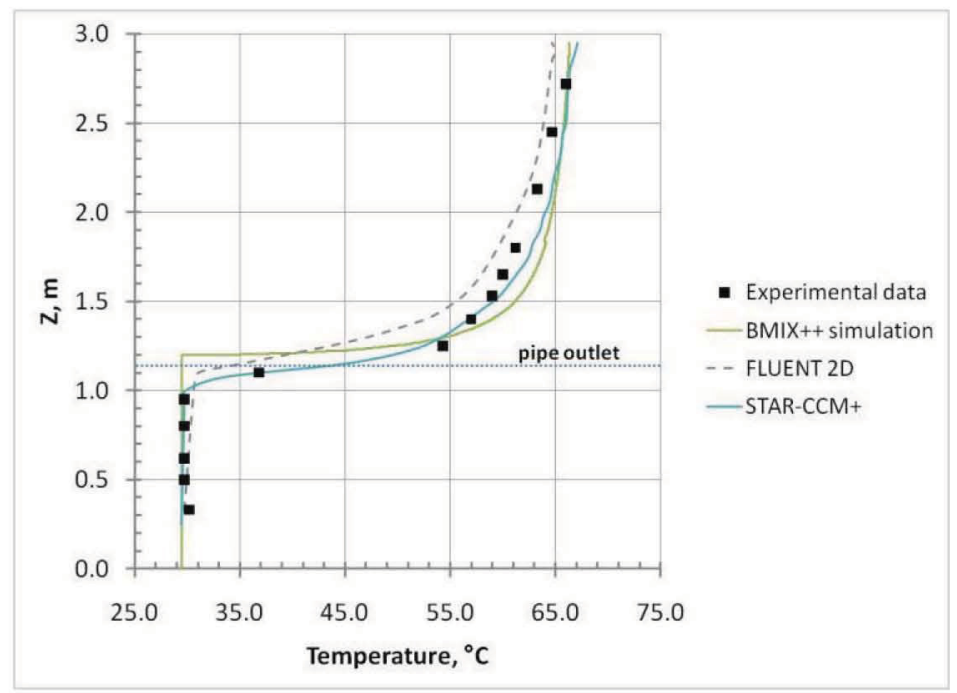

Figure 9. BMIX++ simulated results.

Unlike computationally expensive CFD-based methods, the proposed, one-dimensional, stratification models result in much improved accuracy over zero-dimensional methods, with much less effort than CFD methods. The one-dimensional thermal stratification models are actually one of the successfully implemented examples of the coarse-grain-based models, which use CFD methods but do not resolve boundary layers. The scaling-based method is generic and can be extended into complex mixing scenarios in a stably stratified volume. Therefore, these one-dimensional models can become a component in a large system analysis code (e.g., RELAP) with relative moderate development efforts. The project risk can be minimized by taking advantage of over a decade of research in the thermal mixing and stratification field at the University of California Berkeley, world-class expertise on advanced numerical methods and simulation at INL, and a large amount of a new separate and integral-effects test database. Because thermal stratification modeling also is very important for reactor safety analysis in Gen IV reactors, success of the LWR containment applications can be extended into these fields.

The proposed development efforts will be aimed at four major goals: (1) extend the BMIX++ code's capability for LWR containment applications by including specific jet models with phase change; (2) adapt the BMIX ++ code models to become components in a system analysis code such as RELAP5 or R7; (3) use the tools to investigate complex mixing phenomena in LWR containments; and (4) use advanced numerical methods currently being developed for R7 to improve numerical simulation accuracy and stability. Additional work includes investigating transition models between a well mixed situation and a stably thermal stratified situation (e.g., a recirculation speed model [Niu et al. 2007] or coarse-grid, three-dimensional models).

\subsection{Adverse Flow Effects}

To increase the power output of a reactor, typically, more highly enriched uranium fuel or more fresh fuel is used. This increases the reactor power density and, consequently, enables the reactor to produce more thermal energy and more steam, driving a turbine generator to produce more electricity. In BWRs, the increased core power is achieved by increasing the core feed water flows and steam flows. The degrees of recirculation can be retained with larger steam voids in the cores or the steam volume fractions can be held constant by increasing the re-circulation flows. In PWRs, the increased power outputs call for an increase either in the core coolant flows or in the mean coolant temperature rise across the cores. In order to accomplish this, components (e.g., core internals, pipes, valves, reactor coolant pumps, heat exchangers, electrical transformers, and generators) must be able to accommodate the conditions that would exist at the higher power level. In some instances, large power uprates have resulted in accelerated 
equipment degradation due to increased thermal fluid flows and energy levels. The steam flows from BWR pressure vessels or PWR steam generators will increase, resulting in increased pressure drops and greater dynamic loadings on some components and systems (e.g., increased flow-induced vibrations in the core internals and steam generators). The effects are mostly non-linear. Other issues include

flow-accelerated corrosion on piping and valves. Flow-accelerated corrosion is caused by an increase in turbulence excitation forces (i.e., vortex shedding). These phenomena are called "adverse flow effects" and are challenges associated with EPUs (NRC 2010). In some cases, there were latent effects that took a long time to be detected after completion of an uprate project.

Equipment degradation is caused by high-cycle fatigue through resonance, acoustics, and pressure fluctuations. Most significant problems occurred at Dresden Units 2 and 3 and Quad Cities Units 1 and 2, which experienced failures of steam dryers and electromatic relief valves during EPU operations. Plant experience has shown that as the higher velocity main steamline flow passes over branch lines, it can create an acoustic resonance in the steamlines that can vary greatly from one plant to another, depending on routing of the main steamlines and the steam dryer vintage and geometry. The acoustic resonance can create pressure waves that strike the steam dryer with significant force in BWRs. This force could cause stress in the steam dryer to exceed the material fatigue limits, which may result in steam dryer cracking. The acoustic resonance also can cause excessive vibration that may damage steamline and feedwater line components, such as relief valves and piping. To address this issue, BWR applicants for EPUs have provided complex steam dryer analyses to demonstrate the structural integrity of the steam dryers at uprated power levels. However, it has been challenging for plant owners (i.e., licensees) to provide acceptable steam dryer analyses due to large uncertainties with existing analysis tools. This has significantly contributed to the delays in EPU reviews for several BWR plants. Reasons for these delays typically include licensees introducing new refinements to analytical methods not used in previous EPU applications, NRC identifying new issues with licensees' acoustic circuit models, licensees needing to make steam dryer modifications to address analysis issues, and a lack of adequate plant measurement data needed for steam dryer analyses (NRC 2010). In addition, other BWR core internal components (e.g., feedwater sparger, jet pump, core spray sparger, core spray piping, fuel assembly, shroud head guide rods, and instrument nozzles) also are subject to flow-induced vibration and acoustic vibration. Main steam line, associated components (e.g., main steam isolation valve, power-operated relief valves, high-pressure coolant injection, and reactor core isolation cooling isolation valves), and attached piping also may be susceptible to flow-induced vibration due to EPU. Increased recirculation pump vane passing frequency on the BWR jet pump sensing lines and jet pump riser brace also induces pressure pulsations.

Flow-induced vibration on steam separators/dryers inside PWR steam generator and primary/secondary heat exchanger tubes (e.g., u-bend tubes) also is a concern for power uprates. European PWRs have experienced steam generator divider plate cracking. There also are concerns on acoustic resonance generation during power ascension and dynamic pressure loads on components inside steam generators. Power uprates increase the potential for fretting failures of PWR fuels. Clad failure is caused by flow vibration-induced, rod-spring interactions amplified by irradiation-induced grid spacer growth, and spring relaxation.

Fluid-induced and acoustic vibrations, as well as erosion-enhanced corrosion, is one area that needs fundamental understanding and detailed modeling work assisted with experiments necessary to develop mitigation strategies.

Flow evaluation of three-dimensional thermal fluids and structure interaction methods need to be developed to model the consequences of changes associated with power uprating (e.g., increased core flow and increased feedwater flow). A very important emphasis will be on verification, validation, and uncertainty quantification of the models. Acoustic analysis and experiments are needed to evaluate dryer acoustics and flow-induced vibration to fully uncover the mechanism behind incidents of dryer failure and to develop a method for predicting the consequences of power uprating. 
Other improvements include advanced component designs such as steam dryers and separators that can handle the uprated power output. For instance, a low-pressure-loss separator able to provide both adequate steamwater separation performance and lower pressure losses even when power uprating increases the steam flow rate.

To develop the necessary analytical tools, interaction with CASL, which is the DOE Energy Innovation Hub for Modeling and Simulation, is critical. CASL applies existing modeling and simulation capabilities and develops advanced capabilities to create a usable virtual reactor environment for predictive simulation of LWRs. This environment (known as the Virtual Environment for Reactor Analysis) incorporates science-based models, state-of-the-art numerical methods, modern computational science and engineering practices, uncertainty quantification, and application to existing operating PWRs. The specific applications driving Virtual Environment for Reactor Analysis development are targeted challenge problems that are focused on enabling power uprates and lifetime extension, both plant and fuel, as well as providing a significant improvement in the predictive modeling and simulation capability supporting nuclear energy development. To deliver on its mission within the prescribed time and budget constraints, CASL has elected to focus on solving challenges that originate within the nuclear reactor pressure vessel (i.e., the components that form the heart of a nuclear power plant). Much of CASL's Virtual Environment for Reactor Analysis being developed will provide the foundations for later application to other nuclear power plant types, in particular BWRs. The current focus of CASL is to use its multi-scale, multi-physics capability (i.e., Virtual Environment for Reactor Analysis) to simultaneously couple and solve the neutronics, thermal-hydraulics, fuel thermo-mechanical, structural, materials, and chemistry behavior inside the core of PWRs. Such a capability is envisioned to help quantify design margins and reduce the level of conservatism that must be applied to account for the shortcomings of current design and analysis approaches. One of the challenge problems CASL addresses is the spacer grid to fuel rod fretting failure, which is caused by fluid-induced vibration of spacer grids and interaction with fuel rod cladding. The advanced simulation tools developed by CASL are applicable to address adverse effects.

\subsection{Departure from Nucleate Boiling Characterization}

One of the thermal design limits for PWRs is related to the critical heat flux to prevent the occurrence of DNB, which leads to an abrupt and dramatic degradation in heat transfer from fuel cladding to the coolant. Currently, three major methods exist for predicting the CHF values (i.e., empirical correlations, table look-up technique, and theoretical models [mainly phenomenological models together with a subchannel analysis]). The empirical correlation approach has been widely adopted in practical applications, mainly because the correlations developed by vendors seem to predict the CHF values for their fuel designs more accurately than other methods. Figure 10 shows a lower power than the DNB CHF value set as the limiting condition for operation in a power plant to account for uncertainties arising from the CHF correlations, operational transient, instrumentations, and engineering (Shuffler et al. 2006).

Reactor vendors have separately developed and tested CHF correlations for their own representative fuel designs, including rod bundle geometries and spacer grids with specified applicable conditions. For instance, the W-3 correlation (Tong et al. 1966, Tong 1967, and Ahn and Jeun 2001) was proposed for a Westinghouse fuel design and the CE-1 correlation (Lawrence et al. 1977) was used to estimate the CHF limit for combustion engineering fuel bundles. Some available CHF models were reviewed by Tong and Tang (1997) in detail, and model predictions were compared with results from RELAP5 code by Ferrouk et al. (2008). With the increase of reactor thermal power, the average heat flux from fuel rods is usually increased, which leads to a reduced safety margin as far as the CHF limit is concerned. For example, in the power uprate application for the Ginna nuclear power plant, the approved thermal power uprate is $16.8 \%$ (NRC 2006). The fuel rod's outer diameter was increased from 0.4 to $0.422 \mathrm{in}$. and the active fuel length was changed from 141.4 to 143.25 in. These changes result in an average increase of the heat flux from the fuel rod by about $4 \%$. On the other hand, the total coolant flow rate through the core was not considerably changed (from $60.4 \times 10^{6}$ to $60.6 \times 10^{6} \mathrm{lb} /$ hour at one core outlet temperature condition). The 
increase of the fuel rod outer diameter reduces the coolant flow area, which leads to an increased mass flux and, in turn, may help meet the DNB design limit. However, different nuclear power plants may adopt different approaches in modifying the existing reactor design and operation parameters for a power uprate. In addition, utilities in the future may consider a larger power uprate than 15 to $20 \%$. All of these certainly warrantee a more accurate quantification of $\mathrm{CHF}$ values at various conditions during both normal and off-normal operations. In the following subsections, some potential issues on the established DNB correlations are discussed.

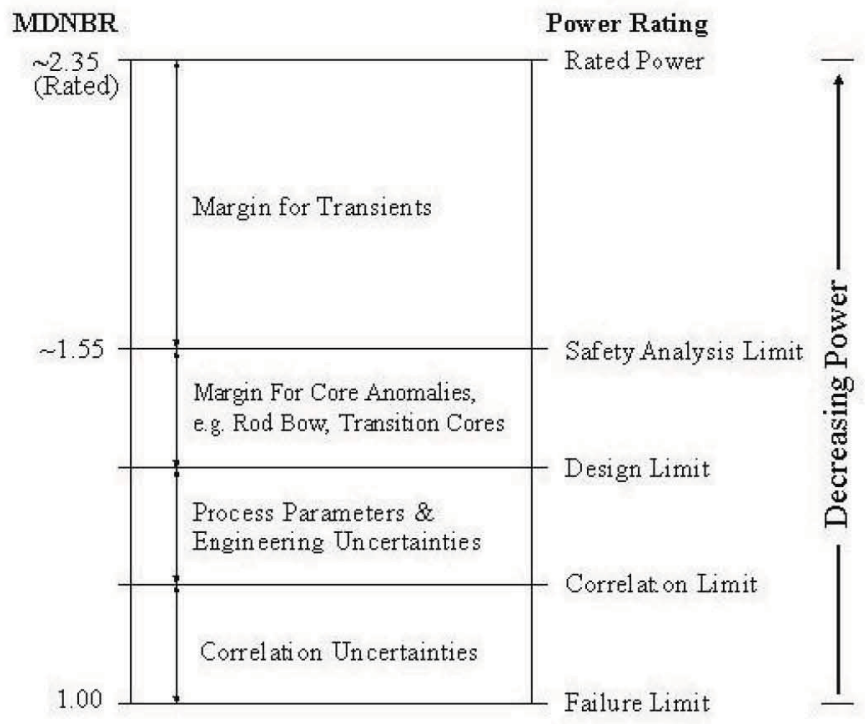

Figure 10. Thermal margins for MDNBR (Shuffler et al. 2006).

\subsubsection{Changes of Operating Conditions Due to Extended Power Uprates}

EPU usually will change some key thermal hydraulic parameters of a nuclear power reactor (e.g., either an increase in the coolant mass flow rate, an increase of the enthalpy rise [or temperature rise] of the coolant through the core, or a combination of these two). Therefore, it raises the question of whether the currently employed CHF correlations are still applicable to the modified operating conditions.

From the NRC reports, most operating PWRs mainly increase the enthalpy/temperature rise of the coolant through the core for their EPU implementations. The changes in enthalpy/temperature rise are relatively small, yielding a situation where current CHF correlations are still applicable to these new conditions at higher power levels. However, it is highly possible that future, more-significant EPUs may result in a considerable increase in the coolant mass flow rate, which may challenge the applicability of the available DNB correlations. As shown in Figure 11 (Han et al. 2006), some correlations become unreliable when the mass flux is larger. Here, $R$ is defined as

$$
R=\frac{q_{\text {predicted }}^{\prime \prime}}{q_{\text {measured }}^{\prime \prime}}
$$

where $q_{\text {predictec }}^{\prime \prime}$ and $q_{\text {measur }}^{\prime \prime}$ are the predicted and measured CHF values, respectively, with the conventional PWR rod bundles of Electric Power Research Institute in either a $5 \times 5$ or $4 \times 4$ array. The W3 correlation underestimates the CHF value by at least $10 \%$ when the mass flux is more than $4,000 \mathrm{~kg} / \mathrm{m}^{2}-$ $\mathrm{s}\left(2.95 \times 10^{6} \mathrm{bb} / \mathrm{ft}^{2}\right.$-hour $)$. In view of this, it becomes essential to carry out additional studies on the DNB correlations at higher mass flux conditions. 


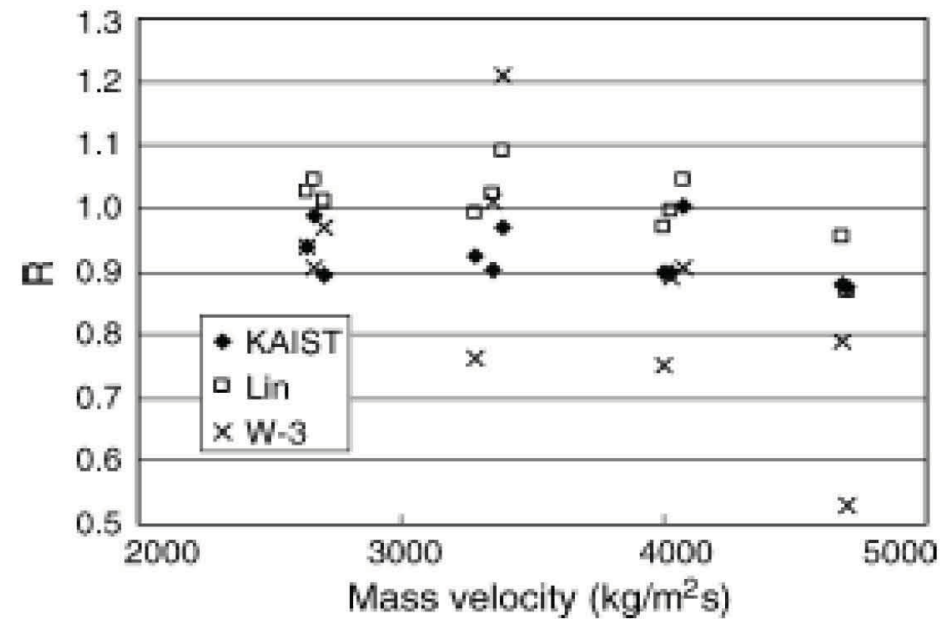

Figure 11. Critical heat flux predictions at a pressure of 14.5 MPa (Han et al. 2006).

\subsubsection{Mixed Types of Fuels During Power Uprates}

In Ginna's application for power uprate, the original Westinghouse optimized fuel assembly was replaced with the Westinghouse $14 \times 14$ Vantage $+(422 \mathrm{~V}+$ ) fuels (NRC 2006). A similar approach to power uprate may be adopted by other nuclear power plants in the future. If old fuels are partially replaced by a new type of fuels in one refueling process (one-third of the fuel is replaced in a typical refueling process for a PWR), mixed types of fuels may exist in the core for the subsequent cycles. The difference in fuel design parameters would potentially alter the radial power shape and coolant flow distributions, which affect the DNB values. Cross flows introduced by flow redistributions also should be taken into account in modeling and predicting DNB-type CHF.

\subsubsection{Effects of Spacer Grids}

The presence of spacer girds with/without mixing vanes generally improves CHF performance. It was discussed by Ahu and Jeun (2001) that two mechanisms contributed to enhanced CHF and were treated separately in the subchannel analysis. The first mechanism was promotion of mixing of flows by increasing flow resistance and was taken into account in the modeling by applying a mixing coefficient. Generation of additional flow vortices decreased the thickness of the bubble layer on the rod wall, which was considered as the second mechanism and treated empirically. Ahu and Jeun (2001) further proposed a function of three parameters to account for the effect of spacer grids: distance between two neighboring grids, distance from the last upstream grid to the CHF location, and equivalent hydraulic diameter. Their model demonstrated appreciably good agreement.

Attention is brought to the case where generation of secondary flow vortices plays a major role. Under this circumstance, downstream turbulence of a certain spacer grid and its interactions with bubbles (that can result in coalescence and disintegration of bubbles) and effects on the liquid velocity distribution close to the rod wall can be analyzed for better understanding of the DNB phenomenon. The vortex shedding also might introduce additional flow instability, which reduced CHF values by $40 \%$, as observed by Ruddick (1953). The effects of the spacer grids on DNB should be accounted for based on the grid design and the local coolant flow behaviors.

Furthermore, it is of importance to investigate and optimize the design parameters of spacer grids (such as type and grid spacing) to enhance DNB limits. A recent discussion related to this work can be found in the paper by Chang et al. (2006). 


\subsubsection{Fuel Rod Vibrations}

Fuel rods experience vibrations, mainly due to coolant flow. The natural frequency of the vibrations highly depends on the fuel rod's physical properties. Kim and Kim (2005) developed an equation to calculate the natural frequencies of the fuel rods and validated it with various boundary conditions. Vibrations may promote bubble coalescence or breakup, modify the frequencies of bubble departure and liquid rewetting, and influence turbulent mixing.

The impact of mechanical vibrations on the heat transfer performance was investigated experimentally by Lee et al. (2004). They found out that vibrations of a vertical round tube increased the DNB value by as much as 10 (Figure 12 ). Here, the so-called vibrational Reynolds number $\left(\operatorname{Re}_{\mathrm{v}}\right)$ is defined as

$$
\operatorname{Re}_{V}=\frac{a w D}{v}
$$

where $a, w, D$, and $v$ denote the sinusoidal displacement of vibration amplitude, vibration frequency, tube inner diameter, and kinematic viscosity of fluid, respectively.

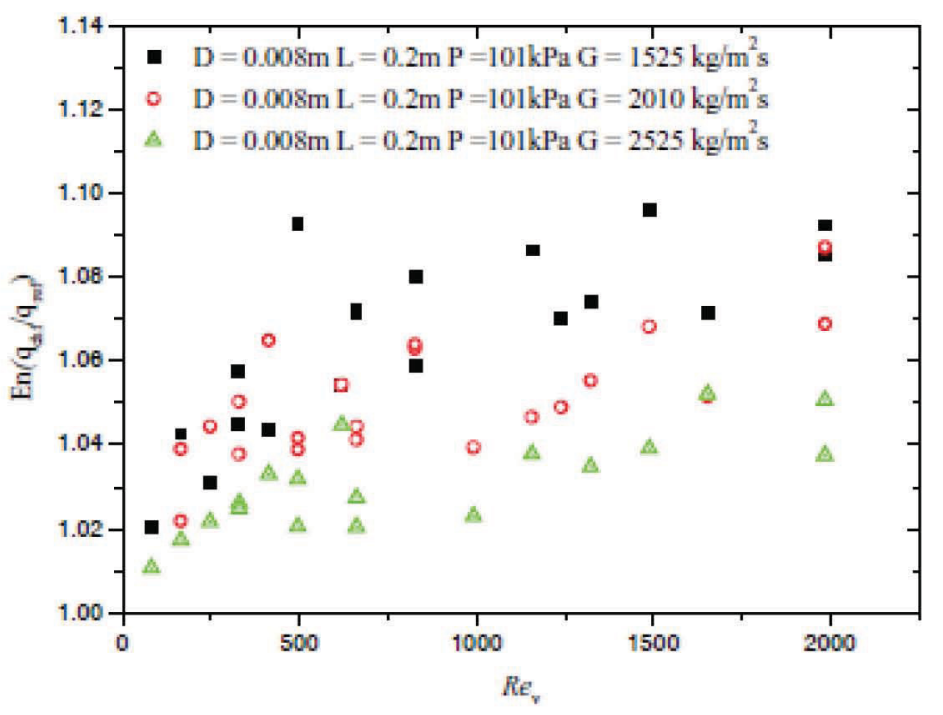

Figure 12. Critical heat flux enhancement ratio versus the vibrational Reynolds number at a departure from nucleate boiling condition.

However, this CHF enhancement mechanism is missing in the existing CHF correlations. It is possible to propose a correction factor to account for this CHF enhancement mechanism due to fuel rod vibrations. This factor would be related to the bubble departure diameter and frequency, natural frequency of the fuel rod, and vibrational Reynolds number. It also is noteworthy to mention that the fundamental frequency of the fuel rods may change due to the rod temperature change, which is generally expected to occur in the plants after power uprate.

\subsubsection{Determination of Inception of Local Boiling}

In the W-3 or other correlations that employ the F-Factor first proposed by Tong et al. (1966), the subcooled boiling length, defined as the distance between the inception of the local boiling and the DNB location, is required. However, the location where the local boiling starts to occur was simply considered as the channel entrance (Tong and Tang 1997). Inaccurate subcooled boiling length values result in uncertainties in the evaluation of the F-Factor and further the CHF value for fuel bundles. A systematic 
study should be performed to determine the onset of local boiling, which may be related to boiling surface properties, subcooling at the inlet, heat flux, and mass flux if the W-3 correlation is to be adopted. As boiling phenomena are controlled by the interfaces at small scales, a micro-scale (or even nano-scale) analysis, focusing on the physical mechanisms of boiling and evaporation of liquid layers on a heating surface, may be conducted.

\subsubsection{Fuel Bowing}

The effects of fuel bowing are usually included in the DNBR calculation. For instance, ANO-2 considers bowing penalties as a function of assembly burnup through the methodology described in "Revised Rod Bow Penalties for Arkansas Nuclear One - Unit 2." Xiao et al. (2004) investigated the importance of fuel bowing to CHF for a PWR. They argued that the effect of fuel bowing was particularly significant when the local quality was low (Figure 13).

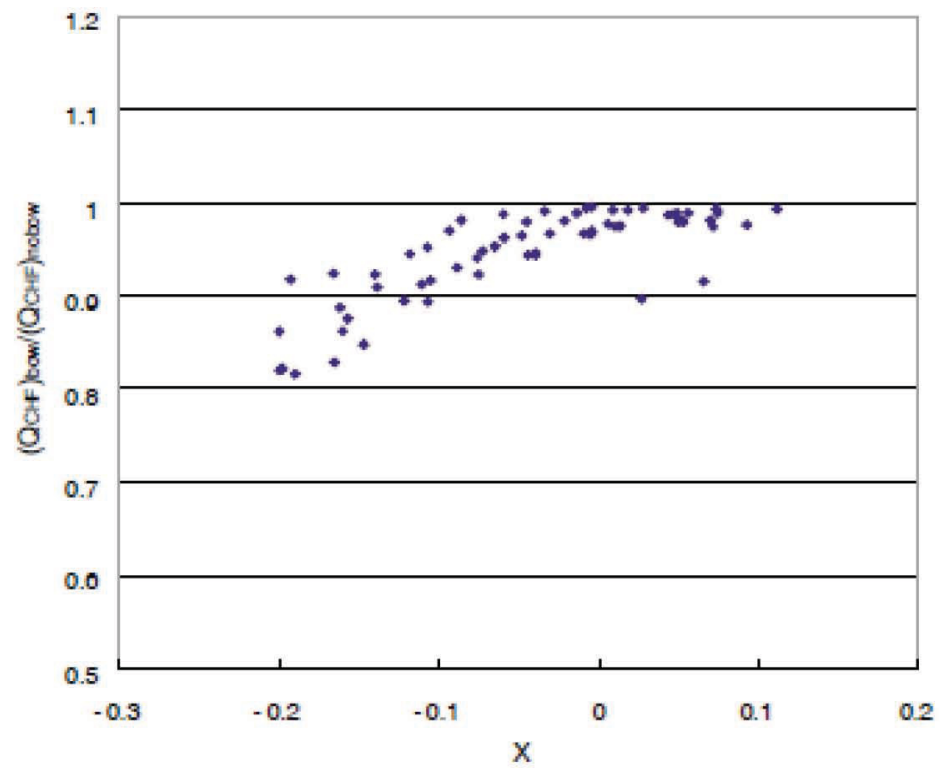

Figure 13. Critical heat flux ratio versus local quality.

\subsubsection{Axial Power Offset}

The CHF correlation developed by Weisman and Ying (1985) considers the axial power offset. However, this correlation is applicable to the rod bundles with simple spacer grids. Later, Hwang et al. (2001) proposed a correction-factor model for non-uniform axial heat flux and validated it with data from a rectangular channel, channel tubes, and rod bundles.

\subsubsection{Surface Characteristics}

Heating surface provides the active nucleation sites. The surface characteristics are closely related to the bubble departure frequency and size and nucleation site density. As fuel rods age with increased radiation fluence, their surface characteristics will change. In addition, the crud formed and deposited on fuel rod clad surfaces (and boron precipitation) will considerably affect the DNB characteristics and need to be taken into account. However, most existing DNB-type CHF correlations were developed with off-pile experiments (the radiation and crud effects were not involved in these experiments). 


\subsubsection{Water Chemistry}

Previous CHF-related experiments mainly focused on deionized water as the coolant. Some earlier experiments have shown that additives to coolant, in particular surfactants, could have a strong impact on bubble nucleation, growth, and heat transfer on the heated wall surface. It becomes desirable and even essential for power uprate applications to examine the DNB-type CHF under realistic PWR conditions, where boric acid and lithium hydroxide are added into the coolant for reactivity control. For EPU PWRs, the initial boric acid concentration may be higher than a typical PWR.

\subsubsection{Future Research Needs on Departure from Nucleate Boiling-Type Critical Heat Flux}

EPUs (i.e., 20\% or above) are believed to considerably reduce the safety margin of PWRs for the rod surface heat flux design limit. In addition, regulatory practice in the United States has moved from low fidelity analysis tools that relied heavily on empirical tuning and conservative modeling toward the use of best estimate analysis with uncertainties. These require us to be able to more accurately model and predict the DNB values for realistic PWR conditions, both normal and off-normal, with uncertainties carefully identified. It becomes essential to revisit the DNB-type CHF issue by conducting more realistic experiments followed by physics-based mechanistic modeling. Therefore, it is proposed that DNB-related experiments be performed first with a focus on the following aspects in the near term:

1. Experiments with prototypic coolant chemistry using fuel bundle geometry and dimensions and a sufficiently broad range of coolant mass flux

2. Effects of the spacer grid design and spacing

3. Effects of the rod surface characteristics with crud deposition and boron precipitation

4. Effects of the axial surface heat flux profile

5. Effects of rod vibration due to coolant flow impact.

\subsection{Spent Fuel Pool Criticality Margin and Coolability}

More sophisticated fuel assembly designs are required to accommodate EPUs and increased capacity factors. These include increased U-235 enrichment, increased fuel pellet diameter, increased fuel pellet density, increased use of fixed and integral burnable absorbers, and increased number of fuel rods in an assembly. All of these changes are leading to increased reactivity of discharged fuel assemblies to be stored in the spent fuel pool. Because the dimensions of the spent fuel pool cannot be changed so that utilities are putting more fuel assemblies into the same volume using high-density storage racks with less spacing between fuel assemblies, the new rack designs heavily rely on permanently installed neutron absorbers to maintain criticality requirements. Unfortunately, virtually every permanently installed neutron absorber material (e.g., Boraflex and Carborundum) have exhibited some degradation. Some have lost a significant portion of their neutron-absorbing capability. In some cases, the degradation is so extensive that the permanently installed neutron absorber can no longer be credited in the criticality analysis. Additionally, due to lack of physical measurements and poorly validated prediction models, the level of degradation is not well characterized. These have resulted in reduced conservatism/margins to criticality, reducing or eliminating the ability to use engineering judgment when determining that there is reasonable assurance an inadvertent spent fuel pool criticality cannot occur. In addition, due to the lack of benchmark data, large uncertainties associated with spent fuel pool analyses also decrease the margin to criticality.

Increased complexity of storage configurations and more reactive spent fuel-forced utilities take credit for items that previously were not part of a spent fuel pool criticality analysis in their license amendment request, such as increasing amounts of soluble boron, cooling time, Pu-241 decay, Am-241 buildup, axial blankets, integral burnable poisons on fresh fuel assemblies, and increased burnup. 
The practice of criticality safety analysis involves the use of criticality data derived from experiments and associated calculations. A typical analysis also will include calculations solving the neutron transport equation, employing either the Monte Carlo method or deterministic methods. Both kinds of calculations require computing the fission distribution iteratively until it is sufficiently converged. A deterministic method is finished when the eigenvalue convergence and source convergence (spatial fission distributions) criteria are met. A Monte Carlo method requires statistical sampling after acceptable source convergence has occurred. Because of the limited computing power when these computer codes were developed, the deterministic methods only have two-dimensional capabilities and can only analyze relatively small configurations. Monte Carlo methods, on the other hand, can simulate large configurations (such as a spent fuel pool). However, slow source convergence has restricted wide applications of Monte Carlo methods.

The standard practice uses two-dimensional deterministic codes (such as CASMO) to perform criticality calculation and three-dimensional Monte Carlo codes (such as KENO) to benchmark the results. The other approach is to use KENO to model the spent fuel pool storage configurations.

Two-dimensional deterministic codes are used to perform depletion analyses to generate the isotopic concentrations that represent the axial burnup distributions in a fuel assembly and the determination of small reactivity increments due to manufacturing tolerances. Two-dimensional deterministic codes are used to simulate in-reactor fuel assembly depletion to calculate the detailed fuel nuclide number densities as a function of fuel depletion and initial feed enrichment. In general, this approach works well because the in-core axial gradient of the neutron flux is small over most of the length of the fuel rod. Conversely, because the axial gradient becomes significant as one approaches either end of the fuel assembly, the twodimensional approximation begins to break down at that point. These codes are widely used for analysis of rack reactivity and have been benchmarked against results from numerous critical experiments.

Existing criticality computer codes suffer two drawbacks: (1) code bias and uncertainty associated with the lack of actinides and fission products data and (2) benchmarking two-dimensional deterministic codes with three-dimensional critical experiments may not be possible. Rather, computer codes benchmarking relies heavily on code-to-code comparisons.

The above discussions lead to the conclusion that high fidelity deterministic codes need to be developed. The codes will be deterministic transport codes with in-reactor fuel assembly depletion simulation to generate detailed fuel nuclide number densities as a function of fuel depletion and initial feed enrichment. The codes should be three-dimensional to simulate the complex fuel assembly storage configurations and validation should be done with three-dimensional criticality experiments and with best available actinide data and fission product data. With the codes developed and validated, the analysis methodology will be changed from conservative approach to best estimate.

\section{PROGRAM SCHEDULE}

Table 1 shows the year by year task priorities and program schedule for the activities presented in this document.

Table 1. Schedule for research and development activities for power uprates.

\begin{tabular}{lccrll}
\hline \multicolumn{1}{c}{ Activity } & Start & Finish & 201120122013201420152016201720182019 \\
\hline Containment response simulation & $10 / 01 / 11$ & $09 / 30 / 15$ & & & \\
Adverse flow effects & $10 / 01 / 14$ & $09 / 30 / 17$ & & & \\
DNB characterization & $10 / 01 / 16$ & $09 / 30 / 19$ & & \\
Spent fuel pool criticality and coolability & $10 / 01 / 16$ & $09 / 30 / 18$ & & \\
\hline
\end{tabular}




\section{REFERENCES}

Ahn, S. H. and G. D. Jeun, 2001, "Effects of spacer grids on CHF at PWR operating conditions," Journal of the Korean Nuclear Society, 33: 283-297.

Andreani, M. et al., 2008, "A benchmark exercise on the use of CFD codes for containment issues using best practice guidelines: A computational challenge," Nuclear Engineering and Design, 238: $502-513$.

Auban, O., R. Zboray, and D. Paladino, 2007, "Investigation of Large-scale Gas Mixing and Stratification Phenomena related to LWR Containment Studies in the PANDA Facility," Nuclear Engineering and Design, 237: 409-419.

Baines, W. D. and J. S. Turner, 1969, "Turbulent Buoyant Convection from a Source in a Confined Region," Journal of Fluid Mechanics, 37: 51-80.

Chang, S., Y. Jeong, and Y. Shin, 2006, "Critical heat flux enhancement," Nuclear Engineering and Technology, 38: 753-762.

Christensen, J. and P. F. Peterson, 2001, "A One-Dimensional Lagrangian Model for Large-Volume Mixing," Nuclear Engineering and Design, 204: 299-320.

Ferrouk, M., S. Aissani, F. D'Auria, A. DelNevo, and A. B. Salah, 2008, “Assessment of 12 CHF prediction methods, for an axially non-uniform heat flux distribution, with the RELAP5 computer code," Nuclear Engineering and Design, 238: 2718-2725.

Gamble, R. E. et al., 2001, "Pressure Suppression Pool Mixing in Passive Advanced BWR Plants," Nuclear Engineering and Design, 204: 321-336.

Han, K., D. Hwang, and S. Chang, 2006, “Assessment of a DNB-type theoretical critical heat flux model for rod bundles with non-uniform axial power shapes," Nuclear Engineering and Design, 236: 223-231.

Hwang, D., C. Park, and S. Zee, 2001, "A phenomenological approach to correcting DNB-type critical heat flux for non-uniform axial power shapes," Int. J. Heat and Mass Transfer, 44: 4483-4492.

Kim, H. and M. Kim, 2005, "Vibration analysis of PWR fuel rod," Journal of Sound and Vibration, 282: $553-572$.

Knoll, D. A. and D. E. Keyes, 2004, "Jacobian-free Newton-Krylov Methods: A Survey of Approaches and Applications," Journal of Computational Physics, 193: 357-397.

Laine, J. and M. Puustinen, 2006, "Thermal stratification experiments with the condensation pool test rig," NKS-117.

Lawrence, F. D. et al., 1977, "Critical heat flux in PWR fuel assemblies," AIChE-ASME Heat Transfer Conference, Salt Lake City, Utah.

Lee, Y. H., D. H. Kim, and S. H. Chang, 2004, “An experimental investigation on the critical heat flux enhancement by mechanical vibration in vertical round tube," Nuclear Engineering and Design, 229: $47-58$.

Mendiola, Anthony, 2011, "Regulatory Perspective on Power Uprates," $2^{\text {nd }}$ Nuclear Power Uprate Conference, Charlotte, June 16-17, 2011.

Morton, B. R., 1959, “Forced Plumes,” Journal of Fluid Mechanics, 5: 151-163.

Mousseau, V. A., 2005, "A fully implicit hybrid solution method for a two-phase thermal-hydraulic model," Journal of Heat Transfer, 127: 531-539. 
NEI-08-10, 2010, "Roadmap for Power Uprate Program Development and Implementation."

Niu, F. et al., 2007, "Investigation of Mixed Convection in a Large Rectangular Enclosure," Nuclear Engineering and Design, 237: 1025-1032.

NRC, 2006, "Safety Evaluation Related to Extended Power Uprate at R.E. Ginna Nuclear Power Plant," accessed in January 2011, http://adamswebsearch2.nrc.gov/idmws/DocContent.dll?library=PU_ADAMS\%5Epbntad01\&LogonI $\underline{D}=\mathrm{f} 69 \mathrm{a} 6 \mathrm{~d} 0 \mathrm{f} 7 \mathrm{~d} 873 \mathrm{a} 96691 \mathrm{f6db2e} 3204 \mathrm{~b} 68$ \&id=061920114.

NRC, 2010, http://www.nrc.gov/reading-rm/doc-collections/commission/secys/2010/secy20100070/enclusure.pdf.

NRC, 2011a, NRC draft guidance for use of containment accident pressure in determining the NPSH margin of ECCS and containment heat removal pumps.

NRC, 2011b, power uprate website. http:/www.nrc.gov/reactors/operating/licensing/power-uprates/typepower.html

NRC, 2011c, Approved Applications for Power Uprates, http:/www.nrc.gov/reactors/operating/licensing/power-uprates/status-power-apps/approvedapplications.html

Oriolo, F. and Paci, S., 1996, "The Safety Margins Evaluation in Next Generation of Nuclear Reactors," IAEA-SR-218/96.

Paladino, D. et al., 2011, "Three-gas Mixture Plume Inducing Mixing and Stratification in a MultiCompartment Containment," Nuclear Engineering and Design, in press.

Peterson, P. F., 1994, "Scaling and Analysis of Mixing in Large, Stratified Volumes," International Journal of Heat and Mass Transfer, 37, 1: 97-106.

"Revised Rod Bow Penalties for Arkansas Nuclear One - Unit 2," 1984.

Ruddick, M., 1953, "An experimental investigation of the heat transfer at high rates between a tube and water with condition at or near boiling," $\mathrm{Ph}$. D. Thesis, University of London.

Shuffler, C., J. Trant, N. Todreas, and A. Romano, 2006, Application of Hydride Fuels to Enhance Pressurized Water Reactor Performance, MIT Technical Report MIT-NFC-TR-077.

Tong, L. S., H. B. Currin, P. S. Larsen, and O. G. Smith, 1966, "Influence of axially non-uniform heat flux on DNB," AIChE Chem. Eng. Prog. Symp. Ser. 62: 35-40.

Tong, L. S., 1967, "Prediction of departure from nuclear boiling for an axially non-uniform heat flux distribution," J. Nuclear Energy, 21: 241-248.

Tong, L. S. and Y. S. Tang, 1997, Boiling Heat Transfer and Two-Phase Flow, $2^{\text {nd }}$ Edition. Francis \& Taylor, Washington, D.C.

Weisman, J. and S. H. Ying, 1985, "A theoretical based critical heat flux prediction for rod bundles at PWR conditions," Nuclear Engineering and Design, 85: 239-250.

Wong, A. B. D. and R. W. Griffiths, 1999, "Stratification and Convection Produced by Multiple Turbulent Plumes," Dynamics of Atmospheres and Oceans, 30: 101-123.

Woodcock, J., Peterson, P. F., and Spencer, D. R., 2001, "Quantifying the Effects of Break Source Flow Rates on AP600 Containment Stratification,” Nuclear Technology, 134: 37-48.

Xiao, Z. et al., 2004, "Experimental research progress on critical heat flux of Chinese PWR," Nuclear Engineering and Design, 229: 213-222. 
Zhao, H., 2003, "Computation of Mixing in Large Stably Stratified Enclosures," Ph.D. dissertation, University of California, Berkeley.

Zhao, H. and P. F. Peterson, 2011, "One-Dimensional Analysis of Thermal Stratification in the AHTR Coolant Pool," Nuclear Engineering and Technology, in press.

Zuber, N., 1991, "An Integrated Structure and Scaling Methodology for Severe Accident Technical Issues Resolution,” Appendix D, NUREG/CR-5809, U.S. Nuclear Regulatory Commission. 